\title{
How (Not) to Elide Negation
}

\author{
Jeroen van Craenenbroeck and Tanja Temmerman
}

April 28, 2016

Abstract. This paper examines the behavior of English negative indefinites under VP-ellipsis. The main empirical observation is that negative indefinites cannot take scope out of a verbal ellipsis site. We propose that negative indefinites involve fusion under adjacency between the clausal polarity head and an indefinite determiner, and that this adjacency comes about under multidominance. Multidominance can feed the morphological coalescence of two syntactic terminals that on the surface do not appear to be linearly adjacent. The claim that there is a morphological relation between these two heads - rather than a syntactic one-is supported by the fact that it can be bled by ellipsis. Given that ellipsis is a PF-process, it can block fusion, thus preventing high scope of negative indefinites out of an ellipsis site.

Portions of this paper have been presented at NELS 41 (University of Pennsylvania, October 2010), the Syntax Circle (Leiden University, June 2011), the Quirky Ellipsis Workshop (University of Groningen, November 2011), and the International Workshop ELLIPSIS2012 (University of Vigo, November 2012). A preliminary version of part of this work can also be found in Temmerman (2012). We would like to thank the audiences of the aforementioned conferences for useful suggestions. We are also grateful to Kyle Johnson, Anikó Lipták, Jason Merchant, Johan Rooryck, Andrés Saab, and the members of CRISSP and GIST for their valuable feedback, and to Chris Barker, Matt Barros, Leston Buell, James Griffiths, Jeremy Hartman, Will Harwood, Kyle Johnson, Allison Kirk, Heidi Klockmann, Jason Merchant, Rachel Nye, Gary Thoms, and Reiko Vermeulen for native speaker judgments. 


\section{Introduction}

This paper provides a novel perspective on the interaction between ellipsis and negative indefinites in English. Consider first a non-elliptical example in (1).

(1) Quentin Tarantino can offer no help.

$$
\left(\neg>\text { can },{ }^{\%} \text { can }>\neg\right)
$$

As indicated by the judgments in the right margin, all speakers we consulted allow the object negative indefinite no help to take scope above the modal can. In addition, a subset of those speakers also allows inverse scope in this example, with the modal outscoping the negative indefinite (see Cormack and Smith 2002, Butler 2003, Iatridou and Zeijlstra 2010, Iatridou and Sichel 2011 for similar judgments, and see section 2.3 for additional discussion). However, when the VP selected by can is elided, only the latter judgment remains (for those speakers that allowed it in the first place):

$$
\text { Q: Who can offer no help? }
$$
A: ${ }^{\%}$ Quentin Tarantino can $\langle$ offer no help $\rangle$.
$\left(* \neg>\right.$ can,${ }^{\%}$ can $\left.>\neg\right)$

So, while the object negative indefinite no help can either scope above or below the modal can in a non-elliptical clause (cf. (1)), it cannot scope above the modal if it is contained in a verbal ellipsis site (cf. (2)). VP-ellipsis thus seems to block high scope of object negative indefinites. This paper investigates these scopal patterns and in so doing, it establishes the following two empirical generalizations:

THE ANY/NO GENERALIZATION

While no can antecede the ellipsis of any in verbal ellipsis, the reverse configuration is disallowed.

The SCOPE GeneralizATION

A negative indefinite in object position cannot take scope outside of a VP-ellipsis site. 
We argue in this paper that negative indefinites should be decomposed into two independent elements, sentential negation (Pol) and an indefinite determiner (D). Their formation is the result of a morphological process, which we refer to as fusion under adjacency. An analysis of English negative indefinites that involves decomposition and fusion might seem surprising at first sight, given that the two components making up the negative indefinite (the clausal polarity marker and the determiner) are not string adjacent in any obvious sense. We propose that the adjacency required for this fusion process is established under multidominance. Moreover, given that fusion is a morphological process, it can be bled by ellipsis. This will form the basis for our account of the generalizations in (3) and (4).

This paper is organized as follows. The next section lays out the central data. It first introduces the general concept of polarity switches under ellipsis (subsection 2.1) and then presents the any/no-Generalization (subsection 2.2) and the Scope Generalization (subsection 2.3). Section 3 provides the background for the analysis. Subsection 3.1 considers possible analyses for negative indefinites and their interaction with VP-ellipsis and points out which aspects of those accounts are problematic in light of the data presented in section 2. Subsection 3.2 introduces Johnson (2012)'s multidominance analysis of wh-movement and Quantifier Raising. Section 4 presents our analysis. Subsection 4.1 introduces the core of the account, in which negative indefinites involve multidominance and fusion under adjacency. In subsections 4.2 and 4.3, we return to the two abovementioned empirical generalizations, and show how the interaction between negative indefinites and ellipsis in English follows from our account. Finally, section 5 sums up and concludes. 


\section{The Data: Negative Indefinites and Ellipsis in English}

This section discusses the behavior of English negative indefinites in verbal ellipsis. ${ }^{1}$ We first provide some background on polarity switches under ellipsis in the next subsection. Subsection 2.2 then deals with the interchangeability of any and no under verbal ellipsis: while no can antecede the ellipsis of any in verbal ellipsis, the reverse configuration is disallowed (i.e. the any/noGeneralization). Finally, in subsection 2.3, we show that negative indefinites in object position cannot take scope out of VP-ellipsis sites (the Scope Generalization).

\subsection{Background: Polarity Switches under Ellipsis}

As is well-known, indefinites and polarity items are interchangeable under ellipsis (cf. Sag 1976, Ladusaw 1979, Hardt 1993, Fiengo and May 1994; Giannakidou 1998, Johnson 2001, Merchant 2013a). Consider the VP-ellipsis examples in (5) and (6). In the example in (5), the antecedent VP contains any, but the elided VP cannot contain this polarity item (cf. (5a)), as this would violate its licensing conditions: any would not be c-commanded by an appropriate licensor. Rather, the elided VP in (5) seems to be equivalent to (5b), with the indefinite some. The reverse situation is shown in (6). Here, the antecedent VP includes the indefinite some, but the polarity item any is required in the ellipsis site (cf. (6a)-(6b)). In short, (5) and (6) show that the negative polarity item any can antecede the ellipsis of the indefinite some and vice versa.

(5) John didn't see anyone, but Mary did.

$$
\begin{aligned}
& \text { a. } \quad * \quad \ldots \text { but Mary did }\langle\text { see anyone }\rangle . \\
& \text { b. } \quad \text {. . but Mary did }\langle\text { see someone }\rangle .
\end{aligned}
$$

[Merchant 2013a:449, (15)]

\footnotetext{
${ }^{1}$ All of the examples discussed in this section involve negative indefinites in object position. As pointed out by Iatridou and Sichel (2011:610), some speakers of English do not accept negative indefinites in object position, regardless of whether ellipsis is involved. This is confirmed by some of our informants, for whom even non-elliptical sentences with an object negative indefinite are degraded. The judgments concerning object negative indefinites reported in this paper are from the subset of English speakers for whom a negative indefinite in object position is acceptable in non-elliptical contexts.
} 
(6) John saw someone, but Mary didn't.

a. $\quad \neq \ldots$ but Mary didn't $\langle$ see semeone $\rangle$.

b. $\quad$... but Mary didn't $\langle$ see anyone $\rangle$.

[Merchant 2013a:449, (16)]

A similar pattern has been observed for the negative indefinite no. Johnson (2001) and Merchant (2013a) note that the elided VPs in (7) do not have a negative meaning, even though their antecedents contain the negative indefinite $n o .^{2}$ The sentences in (7) illustrate that a VP-ellipsis site can include the indefinite $a$ or some while its antecedent contains no. In short, no can antecede the ellipsis of $a$ or some in verbal ellipsis.

(7) a. I could find no solution, but Holly might $\langle$ find *nø/a solution $\rangle$.

[Johnson 2001:468-9, (103)-(104)]

b. "There will be no Paradise for me. But if there were $\left\langle *^{*}\right.$ no/a paradise for me $\rangle$, I wouldn't expect to see you there..."

[Merchant 2013a:453, (25)-(104)]

c. Although John will trust nobody over 30, Bill will /trust *nobødy /somebody over $30\rangle$.

[Sag 1976:312, (4.1.23)]

This concludes our introduction into polarity switches under ellipsis. In the next two subsections we zoom in on two specific subcases of this phenomenon. For a more complete overview of the possible and impossible polarity switches under verbal (and clausal) ellipsis, we refer the reader to Temmerman (2012:51-56).

\footnotetext{
${ }^{2}$ For Merchant (2013a:453), it is not possible "at all" for the ellipsis sites in (7) to contain the negative indefinite no. For Johnson (2001:469), the elided VPs “only marginally" have the negative reading.
} 


\subsection{The any/no-Generalization}

This section investigates the interchangeability of any and no under verbal ellipsis. We show that while no can antecede the ellipsis of any, the reverse configuration is not allowed.

\subsubsection{No can antecede the ellipsis of any}

A verbal ellipsis site can include the negative polarity item any when the antecedent contains the negative indefinite no. This is shown in (8).

(8) a. Many people there have no idea who he was but apparently Obama didn't $\langle$ have any idea who he was $\rangle$ either. ${ }^{3}$

b. " "I have no idea how a hunter would have gotten his hands on it. It makes no sense." — "No, it doesn't $\langle$ make any sense $\rangle . " 4$

c. There was a pause again. Leoni's posture, lying back in the chair, was strained. He asked Starmer: "My authentication, what did you really think about it? You were the only one who made no comment." — "Elvira didn't $\langle$ make any comment $\rangle . " 5$

In all of these (attested) examples - and it is straightforward to find more - the antecedent clause contains a VP with a negative indefinite in object position, while the elided VP most plausibly contains an instance of the NPI any, as is witnessed by the negated auxiliary outside of the ellipsis site.

\subsubsection{Any cannot antecede the ellipsis of no}

Consider the example in (9).

\footnotetext{
${ }^{3}$ http://www.newstatesman.com/blogs/the-staggers/2011/05/special-relationship-visit

${ }^{4}$ http://bleeding-muse.livejournal.com/92002.html

${ }^{5}$ From A Journey South, a novelette by John Christopher (1991). Available at http://www.infinityplus.co.uk /stories/journeysouth.htm
} 
(9) [context: the Cannes Film Festival]

Who didn't like any movie?
a. Quentin Tarantino didn't like any movie.
b. Quentin Tarantino liked no movie.
c. Quentin Tarantino didn't $\langle$ like any movie $\rangle$.
d. *Quentin Tarantino did $\langle$ like no movie $\rangle$.

Although both (9a) and (9b) are licit non-elliptical answers to the question in (9), only the elliptical answer containing any in (9c) is allowed. The answer with no in the VP-ellipsis site in (9d) is ungrammatical.

One could argue that the ill-formedness of $(9 \mathrm{~d})$ is due to the presence of $d i d$, the idea being that a stressed auxiliary is an indication of positive polarity. Note, however, that the effect persists in infinitival VP-ellipsis with a focused subject, as illustrated in (10):

I know PETER didn't offer any help ...
a. .... and I also don't expect JOHN to offer any help.
b. $\quad \ldots$ and I also expect JOHN to offer no help.
c. $\quad \ldots$ and I also don't expect JOHN to $\langle$ effer any help $\rangle$.
d. *... and I also expect JoHn to $\langle$ effer no help $\rangle$.

We conclude from these data that in verbal ellipsis, any cannot antecede the ellipsis of no. Based on the observations in this subsection and the previous one, we present the following empirical generalization:

THE ANY/NO GENERALIZATION

While no can antecede the ellipsis of any in verbal ellipsis, the reverse configuration is disallowed. 


\subsection{The Scope Generalization}

Consider the VPE-examples in (12) and (13):

Q: Who liked no movie?

\section{A: ? Quentin Tarantino did $\langle$ like no movie $\rangle .^{6}$}

(13) I know PETER offered no help, and I also expect JOHN to $\langle$ offer no help $\rangle$.

The sentences in (12) and (13) show that the negative indefinite no can be part of the antecedent of a verbal ellipsis site that contains no as well. In the parlance of the any/no-Generalization, no can antecede the ellipsis of no.

However, if the negative indefinite outscopes an element outside of the verbal ellipsis site, no can no longer antecede the ellipsis of no. Or, in other words, the verbal ellipsis site cannot contain a high-scoping negative indefinite no.

A first case in point that illustrates this concerns so-called 'Neg>Mod-modals', i.e. modals that typically scope below sentential negation (cf. Cormack and Smith 2002, Butler 2003, Iatridou and Zeijlstra 2010, Iatridou and Sichel 2011). As noted by Iatridou and Zeijlstra (2010) and Iatridou and Sichel (2011), the deontic modal can is such a Neg>Mod-modal. That is, for most speakers of English, the sentences in (14) only have a reading in which the negation outscopes can. As pointed out by Cormack and Smith (2002), though, a subset of those speakers also allows the modal to outscope the negation. This speaker variation is indicated by means of a percentage sign.

a. John can not eat vegetables.

$=$ It is not the case that John is permitted to eat vegetables.

$=$ It is permitted that John not eat vegetables.

\footnotetext{
${ }^{6}$ The mild markedness of this example could be due to the fact that, in the case of question-answer pairs, some informants prefer a fragment answer over VP-ellipsis.
} 
b. He can not go to this party.

$=$ It is not the case that he is permitted to go to this party.

$=$ It is permitted that he not go to this party.

As far as negative indefinite DPs are concerned, Iatridou and Sichel (2011) argue that the relative scope of a modal and a negative indefinite DP matches the relative scope of that modal and sentential negation. This generalization is confirmed by our informants for the interaction of the deontic modal can and an object negative indefinite. Most speakers can only interpret the object negative indefinite DP in (15) as scoping over deontic can; a smaller set of speakers also allows the inverse scope reading.

John can do no homework tonight.

$=$ It is not the case that John is permitted to do homework tonight. $\neg>\diamond$

$=$ It is permitted that John not do any homework tonight.

Now consider the case of verbal ellipsis in (16), in which both the antecedent and the VP-ellipsis site licensed by can contain a negative indefinite no. This example is ungrammatical in the reading where negation outscopes the modal $(\neg>\diamond)$ for all speakers. It is only grammatical for those speakers that allow the negation to scope below the modal, and only with that reading (i.e. $\diamond>\neg$ ).

$$
\text { Q: Who can offer no help? }
$$

$$
\text { A: }{ }^{\%} \text { Quentin Tarantino can }\langle\text { өffer no help }\rangle \text {. }
$$

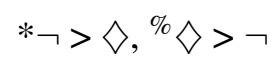

Thus, a negative indefinite inside a VP-ellipsis site cannot take scope outside of that ellipsis site. ${ }^{7}$

\footnotetext{
${ }^{7}$ For a more extensive empirical overview of the interaction between English modals (not only deontics, but also epistemic and dynamic ones), negative indefinites, and verbal ellipsis, providing additional support for the Scope
} 
A second pattern representative of the same generalization can be observed when considering the classic example in (17). The sentence in (17) admits two different readings (cf. Jackendoff 1972, Rochemont 1978), which we refer to as 'the unfortunate dresser reading' and 'the nudity reading':

Mary looks good with no clothes.

= Mary doesn't look good with any clothes.

(unfortunate dresser reading)

= Mary looks good naked.

(nudity reading)

Haegeman (1995) and Svenonius (2002) argue that these two readings correlate with two different scope positions for the negative indefinite no. In the unfortunate dresser reading, the negative indefinite takes high scope and the negation bears on the entire clause. Under the nudity reading, the negative indefinite takes low scope.

In (18), the PP with no clothes is part of an antecedent for VP-ellipsis, and it is contained within the VP-ellipsis site:

You say MARY looks good with no clothes, but I say JULIE does ...

...〈loek good with noclothes $\rangle. \quad$ (*unfortunate dresser, ${ }^{o k}$ nudity)

This example shows that under VP-ellipsis, only the nudity reading survives. Hence, when the negative indefinite is part of a VP-ellipsis site, it can only take low scope. High scope-i.e. scope outside of the ellipsis site-is excluded. More generally, based on the examples discussed in this subsection, we propose the following empirical generalization:

\section{The Scope Generalization}

A negative indefinite in object position cannot take scope outside of a VP-ellipsis site.

Generalization, see Temmerman (2012). She also discusses split scope $(\neg>$ modal $>\exists)$ vs. wide scope $(\neg>\exists>$ modal) readings of negative indefinites, a topic that will not concern us here. 


\subsection{Summary}

In this section we focused on the behavior of English object negative indefinites in verbal ellipsis. Based on the data discussed in subsections 2.2 and 2.3, we arrived at the following two empirical generalizations:

\section{THE ANY/NO GENERALIZATION}

While no can antecede the ellipsis of any in verbal ellipsis, the reverse configuration is disallowed.

\section{The Scope Generalization}

A negative indefinite in object position cannot take scope outside of a VP-ellipsis site.

In what follows, we provide an account for these generalizations. We argue that negative indefinites are formed through a morphological process, called fusion under adjacency, that is bled by verbal ellipsis. The next section provides the background for the analysis.

\section{Background for the Analysis}

\subsection{Possible Analyses of Negative Indefinites and Their Interaction with Verbal Ellipsis}

Both generalizations discussed in the previous section crucially concern negative indefinites. As already indicated there, the interpretation of a negative indefinite does not always correspond to its surface position. For instance, an object negative indefinite can scope above a deontic modal, even though it surfaces to the right of that modal, as in example (15). There are various accounts in the literature of how such a reading comes about, and we review some of them in this subsection.

The traditional view of negative indefinites is that they are atomic lexical elements; more precisely, they are negative generalized quantifiers (see among others Zanuttini (1991), Haegeman and Zanuttini (1991, 1996), Dahl (1993), Haegeman (1995), Geurts (1996), de Swart (2000), von Fintel and Iatridou (2003), Iatridou and Zeijlstra (2010)). The sentence in (22a) is then analyzed 
as in (22b), where the meaning of $n o$ is the generalized quantifier NO in $(22 \mathrm{c}):^{8}$
a. Andy has no enemies.
b. $\quad$ NO (匹enemies $\rrbracket)(\lambda x$ Andy has $x)$
c. $\quad \mathrm{NO}(R)(S)=1$ iff $\forall x: R(x) \Rightarrow \neg S(x)$

[Sauerland 2000:416-417, (1)-(2)]

Negative quantifiers are interpreted just like other, non-negative, generalized quantifiers: in order to obtain sentential scope, the negative indefinite undergoes Quantifier Raising (QR), targeting the same position as other generalized quantifiers (cf. Geurts 1996, de Swart 2000, Iatridou and Zeijlstra 2010).

Another option is to analyze negative indefinites as complex, decomposable lexical items (see among others Jacobs (1980), Rullmann (1995), Giannakidou (1997), Sauerland (2000), Weiß (2002), Tubau (2008), Haegeman and Lohndahl (2010), Johnson (2010), Penka and Zeijlstra (2010), Iatridou and Sichel (2011), Penka (2011), Zeijlstra (2011), Merchant (2013a)). ${ }^{9}$ In particular, while spelled out as a single word, no contains two syntactically and semantically distinct ingredients: (sentential) negation and an indefinite (expressing existential quantification). As such, a sentence containing a negative indefinite is equivalent to a sentence containing a combination of a negative marker and an (NPI) indefinite. ${ }^{10}$ This is sketched for example (22a) in (23a) and paraphrased in

\footnotetext{
${ }^{8}$ For arguments against this approach independent of the one presented here, see Sauerland (2000), Weiß (2002), Iatridou and Sichel (2011), Penka (2011), Zeijlstra (2011).

${ }^{9}$ Note that some of these proposals do not involve actual decomposition. In particular, some take the negative indefinite to be a plain indefinite, which gets a negative interpretation because a covert negative operator licenses it in its scope (via Agree or feature checking, see below). As noted by Iatridou and Sichel (2011:609, fn.12), such accounts can nonetheless be grouped in the 'decomposition camp' because "on these analyses too negation and the existential are syntactically separate."

${ }^{10}$ For the treatment of any as an existential (on a par with a/some) instead of a universal (on a par with every), see Klima (1964), Kamp (1973), and Sag (1976), among others (pace e.g. Quine (1960)).
} 
(23b). Note that the truth conditions of (23a) and (22b) are identical.
a. $\quad \operatorname{NOT}(\exists x \in \llbracket$ enemies $\rrbracket:$ Andy has $x)$
b. 'It's not the case that Andy has an enemy.'
'Andy doesn't have any enemies.'

[Sauerland 2000:417, (3)]

'Decomposed' object negative indefinites are often argued to be the result of Agree or feature checking between a sentential polarity head (an abstract negative operator) and a non-negative indefinite in object position (cf. Giannakidou 1997, Weiß 2002, Tubau 2008, Haegeman and Lohndahl 2010, Penka and Zeijlstra 2010, Penka 2011, Merchant 2013a). The presence of an abstract negative marker is needed to license the indefinite. The semantically non-negative indefinite carries an uninterpretable negative feature $[u \mathrm{NEG}]$ that has to be checked against a (covert) semantic negation, i.e. against an interpretable negative feature $[\mathrm{NEG}]$ on a semantically negative element. ${ }^{11}$ The negative indefinite is therefore the visible result of syntactic agreement, similar to phenomena such as subject-verb agreement or multiple gender marking on e.g. nouns and adjectives (cf. Penka and Zeijlstra 2010:781).

A third possible approach to negative indefinites are the amalgamation/incorporation analyses proposed by Bech (1955/57), Jacobs (1980), and Rullmann (1995). They consider an object negative indefinite to be the result of a fairly superficial process of amalgamation or incorporation between a negative marker and a string-adjacent indefinite determiner. ${ }^{12}$ Rullman's rule for Dutch

\footnotetext{
${ }^{11}$ This proposal goes back to the analyses in, for example, Ladusaw (1992) and Zeijlstra (2004) of negative indefinites (or n-words in Laka's (1990) terminology) in negative concord languages.

${ }^{12}$ The accounts proposed in Iatridou and Sichel (2011) and Zeijlstra (2011) combine a QR-analysis with an amalgamation/incorporation component. In these decompositional analyses, the negative indefinite consists of two separate components, negation and an indefinite. Iatridou and Sichel (2011) take the latter to undergo QR to the position of the former.
} 
negative indefinites is given in (24) (Rullmann 1995:197, (8)), where geen is the negative indefinite 'no', niet is the sentential negative marker 'not', and Det ${ }_{\text {indef }}$ is either the overt indefinite determiner een 'a' or a zero one (used in combination with bare plurals and mass nouns).

$$
\text { niet } \text { Det }_{\text {indef }} \Rightarrow \text { geen }
$$

As noted by Iatridou and Sichel (2011) and Zeijlstra (2011), while neither Jacobs nor Rullmann uses the term 'PF' to describe the component of the grammar where this process takes place, "the prose implies that this is what was intended" (Iatridou and Sichel 2011:626, fn.27). For instance, Rullmann (1995:197) talks about "a relatively superficial level of representation".

We have now introduced three approaches to negative indefinites: a generalized quantifier + QR-analysis, a decomposition analysis that involves Agree or feature checking, and a decomposition analysis based on PF-amalgamation or -incorporation. When considering the interaction between negative indefinites and verbal ellipsis discussed in the previous section, the first two approaches turn out to be problematic. Recall that a negative indefinite in object position cannot take scope out of a VP-ellipsis site (the Scope Generalization). A relevant example was given in (16), repeated here as (25):

Q: Who can offer no help?

A: ${ }^{\%}$ Quentin Tarantino can $\langle$ effer no help $\rangle$. $* \neg>\diamond,{ }^{\%} \diamond>\neg$

Let us first consider how a QR-based analysis would handle these facts. It is well-known that VPellipsis does not block Quantifier Raising, at least not as long as Parallelism (cf. (26)) and Scope Economy (cf. (27), (28)) are respected (see Fox 2000 for extensive discussion).

Parallelism (a consequence of)

In an ellipsis construction, the scopal relationship among the elements in the antecedent must be identical to the scopal relationship among the parallel elements in the ellipsis 
site. $^{13}$

[Fox 2000:32]

Economy condition on scope shifting (Scope Economy)

An operation can apply only if it affects semantic interpretation (i.e., only if inverse scope and surface scope are semantically distinct).

[Fox 2000:21]

\section{The Ellipsis Scope Generalization}

In an ellipsis construction, inverse scope is possible only if it is semantically distinct from surface scope both in the sentence that includes the ellipsis site and in the sentence that includes the antecedent.

[Fox 2000:83]

Parallelism (cf. (26)) ensures that in ellipsis environments, the antecedent and the elliptical clause receive isomorphic representations at LF. Even if sentences are potentially scopally ambiguous, the scopal relationships in the antecedent cannot be different from those in the ellipsis site. Either both the antecedent and the ellipsis site have surface scope or they both have inverse scope. The latter option is only available if Scope Economy (cf. (27), (28)) is obeyed. The sentences in (29) and (30) illustrate how Parallelism and Scope Economy operate in VP-ellipsis. The sentence in (30) is restricted to surface scope, whereas the sentences in (29) are not.

a. A boy admires every teacher. A girl does $\langle$ admire every teacher $\rangle$, too.

[Fox 2000:33, (22e)]

b. Some girl watched every movie, and some boy did 〈watch every movie $\rangle$, too.

[Ha 2007:160, (10)]
(i) $\exists>\forall \& \exists>\forall$
(both conjuncts take surface scope)
(ii) $\forall>\exists \& \forall>\exists$
(both conjuncts take inverse scope)
(iii) $* \exists>\forall \& \forall>\exists$
(Parallelism is violated)

\footnotetext{
${ }^{13}$ Fox (2000) adjusts the principle of Parallelism somewhat in Chapters 3 and 4 of his monograph. For our present purposes, the form in (26) suffices, but see section 4.3 for a slightly refined version and more detailed discussion.
} 


$$
\text { (iv) } * \forall>\exists \& \exists>\forall
$$

(Parallelism is violated)

A boy admires every teacher. Mary does 〈admire every teacher $\rangle$, too.

[Fox 2000:32, (21)]

$$
\begin{aligned}
& \text { (i) } \exists>\forall \& \exists>\forall \\
& \text { (ii) } * \forall>\exists \& \forall>\exists \\
& \text { (iii) } * \exists>\forall \& \forall>\exists \\
& \text { (iv) } * \forall>\exists \& \exists>\forall
\end{aligned}
$$

(both conjuncts take surface scope)

(Scope Economy is violated)

(Parallelism is violated)

(Parallelism is violated)

In both (29) and (30), the interpretations in (iii) and (iv) are unavailable because they violate Parallelism. In order to explain why the sentences in (29) have the interpretation in (ii) available, while the one in (30) does not, Fox (2000) resorts to Scope Economy (and Parallelism):

"The relevant difference between the two constructions, I propose, is that in [(30)] the ellipsis sentence is scopally uninformative. Therefore, Scope Economy restricts the ellipsis site to surface scope, and Parallelism blocks inverse scope in the antecedent sentence. In [(29a) and (29b)], the ellipsis sentence is scopally informative and is therefore unrestricted by Scope Economy. Both the ellipsis sentence and the antecedent sentence can receive inverse scope as long as Parallelism is maintained."

[Fox 2000:34]

Note that in the illicit reading of (32) (i.e. $\neg>\diamond$ ), both Parallelism and Scope Economy are respected:

Q: Who can offer no help?

A: ${ }^{\%}$ Quentin Tarantino can $\langle$ effer no help $\rangle$. $* \neg>\diamond,{ }^{\%} \diamond>\neg$

In particular, inverse scope (i.e. the negative indefinite outscoping the modal) is scopally informative, so Scope Economy is respected. This inverse scope reading is available in the antecedent, so following Parallelism, it should also be available in the ellipsis site. This is corroborated by the 
fact that in the non-elliptical counterpart of (32), inverse scope is freely available:

Q: Who can offer no help?

A: Quentin Tarantino can offer no help.

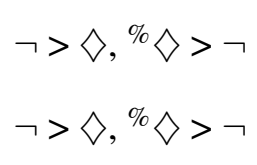

Given that both Parallelism and Scope Economy are respected, QR of the negative indefinite out of the VP-ellipsis site should be allowed, quod non:

Q: Who can offer no help? $\neg>\diamond$ A: * Quentin Tarantino can $\langle$ өffer no help $\rangle$.

In short, an analysis of negative indefinites based on QR cannot account for the Scope Generalization discussed in the previous section. Accordingly, we will not adopt such an approach in this paper.

The Agree/feature checking analysis of negative indefinites turns out to be problematic as well in light of their interaction with verbal ellipsis. In particular, it is well-known that VP-ellipsis does not block Agree/feature checking. For example, T can agree with the elided associate of a there-expletive. In there-expletive constructions, the expletive occupies specTP, while the thematic subject (the associate) remains in the base position inside the $v \mathrm{P}$. When VP-ellipsis applies, the associate is included in the ellipsis site. As is shown in (35), the auxiliary outside of the ellipsis site agrees with the elided associate.

a. I didn't think there were going to be many people at the party, but there were $\langle$ many people at the party $\rangle$.

b. I didn't think there was going to be a famous linguist at the party, but there was $\langle$ a famous linguist at the party $\rangle$.

Note that this is not due to some (obscure) locality or adjacency effect: even a T-head that is 
structurally and linearly far removed from the ellipsis site can still agree with an elided associate:

a. Q: Will there be a linguist at the party?

A: Well, there seems to be likely to be $\langle$ a linguist at the party $\rangle$.

b. Q: Will there be (any) linguists at the party?

A: Well, there seem to be likely to be 〈linguists at the party〉.

a. Q: Will there be an independent investigation of the murder?

A: There seems likely to be $\langle$ anindependent investigation of the murder $\rangle$.

b. Q: Will there be independent investigations (by the CIA, the FBI, ...) of the murder?

A: There seem likely to be 〈independent investigations of the murder $\rangle$.

Given that VP-ellipsis does not interfere with Agree/feature checking, accounts of negative indefinites based on these mechanisms are at a loss to explain why verbal ellipsis prevents negative indefinites from taking high scope. If high scope is the result of Agree/feature checking between (the determiner of) the object and a high polarity head, the examples in (35)-(37) suggest that an ellipsis boundary should be unable to interfere with this process.

More generally, we have now reviewed two syntactic approaches to negative indefinites and have concluded that neither of them can account for the interaction between negative indefinites and ellipsis. Therefore, we will pursue a morphological analysis in terms of fusion (incorporation/amalgamation) instead. The first lexical decomposition analyses, put forward by Bech (1955/57), Jacobs (1980), and Rullmann (1995), propose that an amalgamation/incorporation process merges a negative marker and an indefinite determiner into a negative indefinite. As noted by Zeijlstra (2011:19), their proposals crucially rely on phonological string adjacency between the negation and the indefinite. Not surprisingly, Bech, Jacobs, and Rullman focus on German and Dutch. These are SOV languages, which means that the object and the sentential negation marker are surface adjacent (in particular, the verb does not intervene between them). Given that English is an SVO-language, though, and that the two ingredients of a negative indefinite are not string 
adjacent in any obvious sense, an analysis of English object negative indefinites that involves decomposition and fusion seems problematic. This is illustrated in (38), where sentential negation and (the indefinite determiner of) the postverbal object are separated by the verb.

Vegetarians do not eat any meat.

Given Rullmann (1995:197)'s claim that “incorporation is blocked by lexical material that lies between not and Det ${ }_{i n d e f}$ at the surface" (our translation), the amalgamation/incorporation accounts of Bech (1955/57), Jacobs (1980), and Rullmann (1995) seem ill-suited to deal with object negative indefinites in English. What we will propose instead in section 4 is that the locality/adjacency required for the fusion of the negation and the indefinite is established under multidominance. ${ }^{14}$ Before turning to this analysis, we first introduce the theoretical background for our account: Johnson (2012)'s multidominance account of wh-movement and Quantifier Raising.

\subsection{A Multidominance Analysis of Wh-movement and Quantifier Raising (Johnson 2012)}

Johnson (2012) proposes to model wh-movement with the operation of remerge (i.e. Internal Merge). He argues that remerge resolves conflicting requirements of the semantics and the morphology of constituent questions. It results in a phrase having two mothers, i.e. in multidominance.

Johnson starts out from the idea that constituent questions involve two components: (i) a DP that introduces a variable in a clause-internal position, and (ii) a question morpheme Q in a leftperipheral position that semantically combines with the clause (marking the scope of the question) and binds off the variable introduced by the DP (Hagstrom 1998, Reinhart 1998, Kishimoto 2005, Cable 2007, 2010). In English, the Q-component is phonologically silent; only the variable component (the wh-phrase) is visible. In other languages (e.g. Japanese), both components are overtly realized. In the Japanese example in (39), an interrogative phrase (dono gakuseiga) occupies the

\footnotetext{
${ }^{14}$ Note that the various post-syntactic reordering mechanisms proposed in Distributed Morphology (Halle and Marantz 1993), such as Lowering or Local Dislocation, cannot establish the required adjacency relation either; see Temmerman (2012:142-144) for detailed discussion.
} 
position of the variable and a question morpheme $(k a)$ on the verb marks the scope of the question.

(Kimi-wa) dono gakusei-ga nattoo-o tabe-tagatte-iru-to omoimasu-ka? (you-TOP) which student-NOM natto-ACC eat-desirous-be-C think-Q 'Which student do you think wants to eat natto?'

[Japanese, Johnson 2012:539, (33)]

For Japanese, "we might imagine that the question morpheme and the interrogative phrase are independently merged into the positions that they are pronounced in" (Johnson 2012:539). For English, Johnson adopts Cable (2007, 2010)'s analysis of wh-questions in Tlingit. A wh-phrase in Tlingit occupies a left-peripheral position (like in English), but at the same time the question contains both a wh-determiner and a Q-morpheme (like in Japanese). Unlike the Japanese Q, the Q-morpheme in Tlingit is part of the wh-phrase. This is illustrated in (40): the Q-particle sá has merged with the DP that contains the wh-word aadóo.

[Aadóo yaagú sá] $]_{i}$ ssiteen $t_{i}$ ?

whose boat $\mathrm{Q}$ you-saw

'Whose boat did you see?'

[Tlingit, Johnson 2012:539, (34), citing Cable 2010:44, (67)]

Cable (2007, 2010) proposes that there is an Agree-relation between the Q-particle and the whword. This Agree-relation is subject to a locality condition, which forces the Q-morpheme to be merged directly with the interrogative phrase (see Cable $(2007,2010)$ for details)). In English, this Q-morpheme is silent, and the wh-determiner which is considered to be an agreeing form of D. Put differently, which is the overt spell-out of the Agree-relation between Q and D.

Importantly, Q does not combine semantically with the DP it is merged with. Rather, it needs to combine at a clausal level, to turn the entire sentence into a question. The rest of the $w h$ DP, however, is not interpreted in that higher position; only the Q-morpheme is. In other words, the semantics require that the Q-morpheme and the interrogative DP be more distant than the locality condition on the Agree-relation between them tolerates. These conflicting semantic and morphosyntactic requirements are met thanks to remerge, which results in a multidominant repre- 
sentation. To make this more concrete, consider the structure in (42) for the example in (41).

(41) Which story about her ${ }_{1}$ should no linguist ${ }_{1}$ forget?

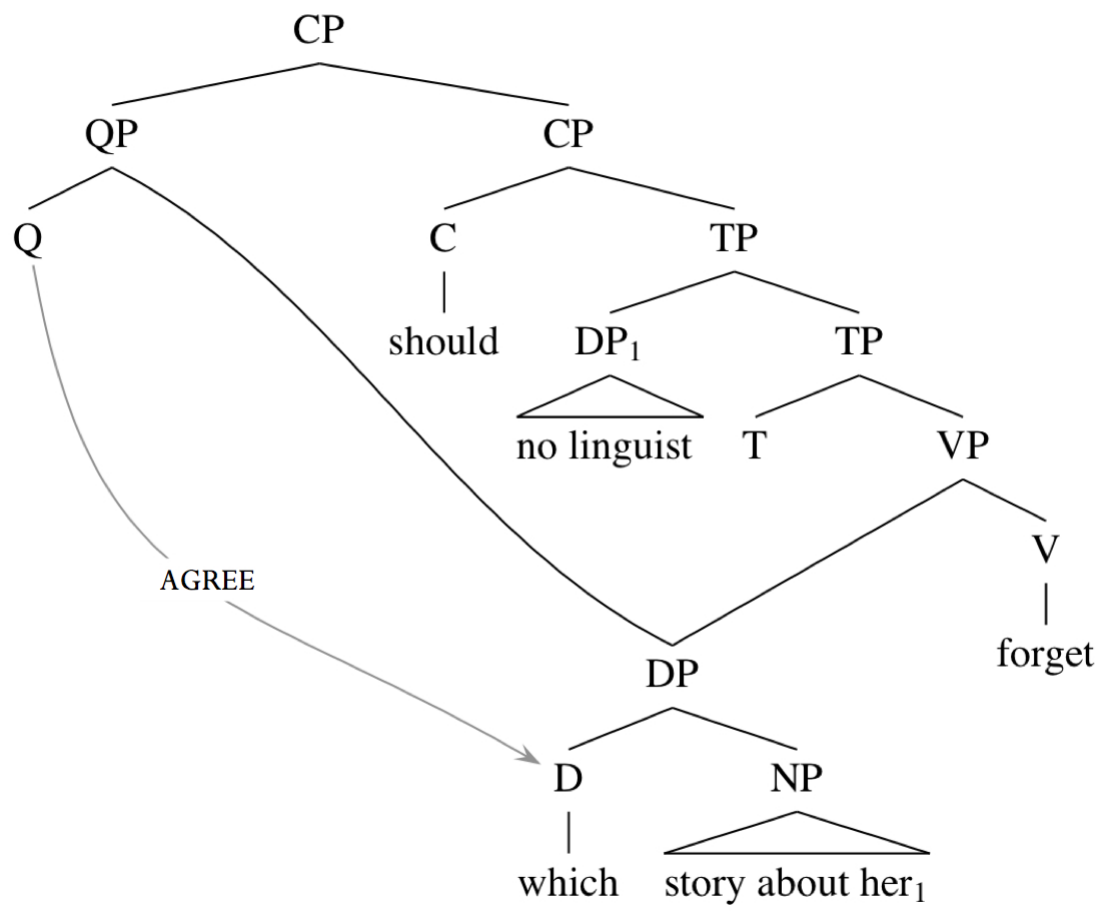

[Johnson 2012:540, (41)]

When linearization applies to the structure in (42), the remerged DP, which is related to two positions, can only be linearized in one of these positions. For the representation in (42), the interrogative DP can either be linearized in specCP or in the base position of the direct object. In a simple constituent question like (41), English chooses the former option, linearizing the interrogative phrase in clause-initial position.

As far as QR is concerned, Johnson proposes that it too involves two components: (i) a DP in a lower position, which has the denotation of a definite description, and (ii) an operator in a higher position that binds this definite description (cf. also Engdahl $(1980,1986)$ and Fox $(2003))$. 
As a generalized quantifier, the operator "combine[s] first with the NP in the quantificational DP and then with another predicate, one that corresponds to the scope of the quantifier" (Johnson (2012:543)). ${ }^{15}$ As shown in the structure in (44) for the example in (43), remerge puts an NP in two structural positions in a sentence containing QR. The determiner in the lower position and the quantifier in the higher position both combine semantically with this NP.

A student read every paper yesterday.

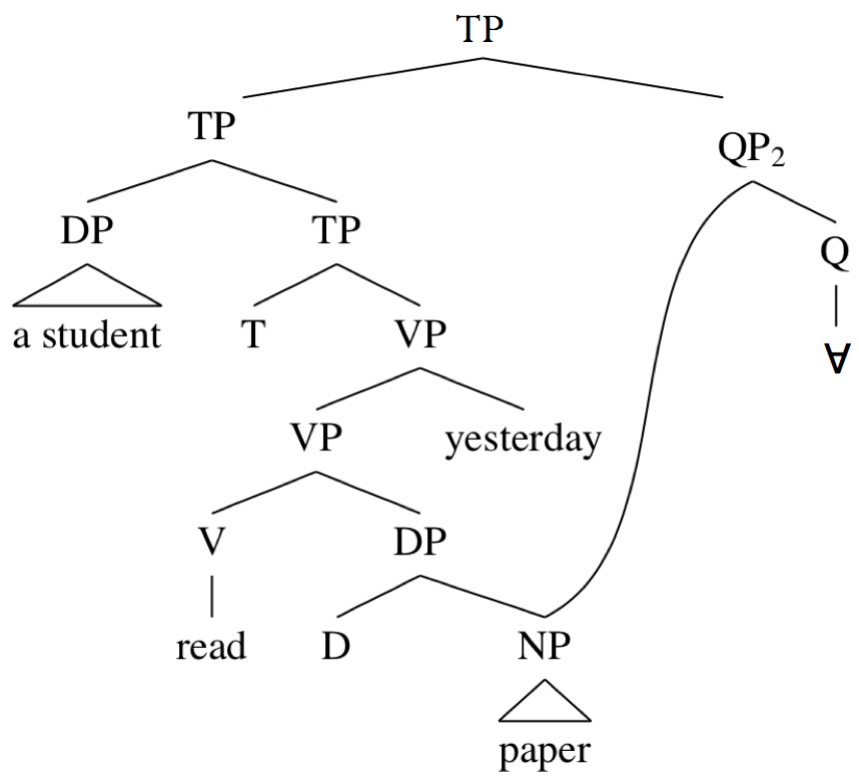

[based on Johnson 2012:543, (48)]

Note that the determiner every in (43) is spread over two syntactic positions in the representation in (44): on the one hand, the D inside the direct object DP, and on the other, the Q heading the

\footnotetext{
${ }^{15}$ As pointed out by Johnson (2012:543n18), this presupposes that "the quantificational part of a quantificational DP can be expressed syntactically in a position different from where the quantificational DP is", see also Williams (1986, 1988), Beghelli (1993), Kitahara (1996), Reinhart (1997). Note also that Johnson's analysis is close in spirit to Kennedy's (1997:669, fn.10) proposal that the syntactic operation QR “is driven by the need to generate a structure that permits the proper interpretation of a quantificational determiner."
} 
QP adjoined to TP. This raises the question of how these two syntactic nodes can be spelled out as one. In particular, given that there is no c-command relation between D and Q in (44), the spell-out of D as every cannot be an instance of an Agree-ing determiner (as was the case for which in whquestions, see above). Instead, Johnson proposes that there is a morphological process, fusion, that combines two terminal nodes into one, which is then realized by a single lexical item. However, based on the structure in (44), it is not obvious how fusion can bring together Q and D, as these heads are clearly not adjacent to one another. Johnson suggests that fusion has to occur before the structure in (44) is built. In particular, the morphological requirements of Q and D force (cyclic) linearization to take place prior to the merger of QP and TP, i.e. at the point of the derivation given in $(45):{ }^{16}$

${ }^{16}$ Johnson (2012:545) formulates it as follows: "I speculate that there is a condition which requires the terminals in a phrase marker to be mapped onto matching morphology. That condition should require the Q holding $\forall$, for instance, to be expressed morphologically. But if the term that expresses $\forall$-let's assume it's every — can only be inserted in a position where $\forall$ and the are fused, then this requirement will not be met in a structure formed by QR. [...] I suggest that this has the effect of forcing fusion to occur before QR builds the offending structure. Because fusion requires of the terms to be fused that they be adjacent, this will also require that the linearization algorithm be run on structures formed before QR has applied". See section 4.2 for further discussion and an alternative. 


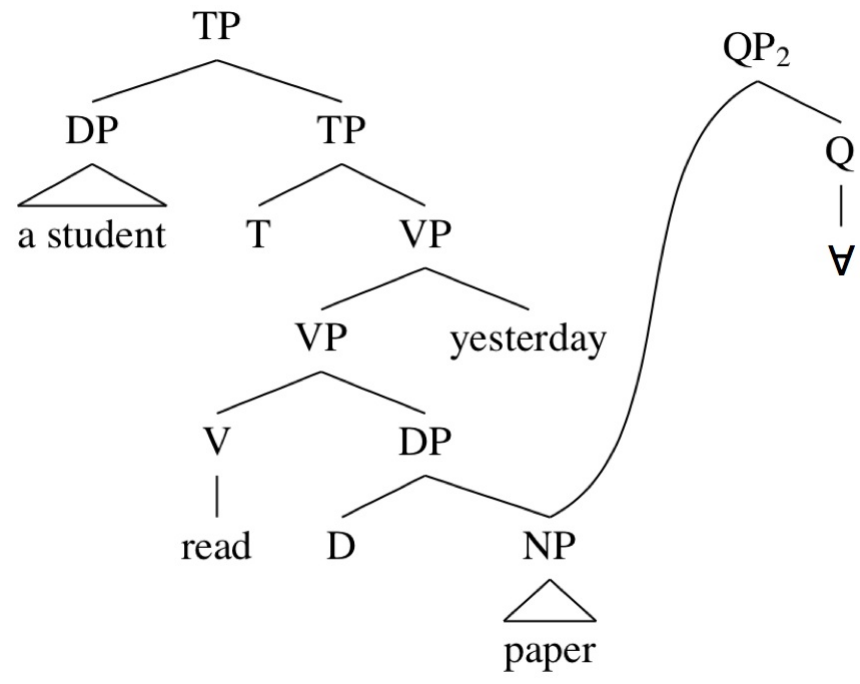

[Johnson 2012:545, (54)]

The result of this linearization procedure is given in (46):

a. The linearization of TP in (45):

$$
\left\{\begin{array}{lll}
\mathrm{a}<\text { student } & \text { student }<\mathrm{T} & \text { read }<\mathrm{D} \\
\mathrm{a}<\mathrm{T} & \text { student }<\text { read } & \text { read }<\text { paper } \\
\mathrm{a}<\text { read } & \text { student }<\mathrm{D} & \text { read }<\text { yesterday } \\
\mathrm{a}<\mathrm{D} & \text { student }<\text { paper } & \mathrm{D}<\text { paper } \\
\mathrm{a}<\text { paper } & \text { student }<\text { yesterday } & \mathrm{D}<\text { yesterday } \\
\mathrm{a}<\text { yesterday } & & \text { paper }<\text { yesterday }
\end{array}\right\}
$$

b. The linearization of QP in (45): $\{\forall<$ paper $\}$

The fusion of two terminals is dependent on a locality condition: they can fuse only if the linearization algorithm assigns them adjacent positions. Johnson defines adjacency as in (47), which can be formally represented as in (48): 
Adjacency

Two terminal items $\alpha$ and $\beta$ are adjacent if the linearization algorithm puts nothing in between them. [cf. Johnson 2012:546, fn.22]

Two terminal nodes $\alpha$ and $\beta$ are adjacent iff $\neg \exists \gamma \cdot((\alpha<\gamma \& \gamma<\beta) \vee(\beta<\gamma \& \gamma<\alpha))$

The linearization algorithm has put nothing in between $\mathrm{D}$ and $\forall$ in (46): there is no node that follows $\forall$ and precedes D or vice versa. Hence, $\mathrm{D}$ and $\forall$ are allowed to fuse and they get mapped onto a single vocabulary item (the quantifier every). This vocabulary item now comes to occupy the positions assigned to $\mathrm{D}$ and $\forall$ in (46). In the end, the linearized string will be $A$ student read every newspaper yesterday, with the QRed phrase spelled out in its original position but interpreted with clausal scope.

This concludes our overview of Johnson (2012)'s multidominant analysis of $w h$-movement and QR. In the next section we apply this line of reasoning to negative indefinites.

\section{The Analysis: Ellipsis Blocks Fusion}

In this section we present our analysis of negative indefinites and their interaction with verbal ellipsis. Subsection 4.1 introduces the core of the account: negative indefinites involve remerge and fusion under adjacency. Because of remerge, the locality required for fusion is obtained, and the negative head and the indefinite can fuse together. In subsections 4.2 and 4.3 , we return to the two empirical generalizations discussed in section 2, and show how the interaction between negative indefinites and verbal ellipsis in English follows from our account. We argue that the PF-process of ellipsis bleeds fusion, thus blocking the formation of a negative indefinite in certain contexts.

\subsection{The Core of the Analysis: Negative Indefinites Involve Multidominance}

Johnson (2010) proposes to extend the analysis outlined in the previous section to negative indefinites. In particular, even though the negative indefinite is spelled out as a single word (i.e. no), it is spread across two distinct syntactic positions: sentential negation and an indefinite de- 
terminer. Moreover, negative indefinites involve a multidominant derivation: the indefinite direct object first merges with the verb and later remerges with sentential negation. The multidominant phrase marker proposed by Johnson (2010) for (49) is given in (50). The Pol-head in (50) combines semantically with VP-it negates the proposition—but morphologically with DP. ${ }^{17}$

$$
\text { She likes no spiders. (= She doesn't like (any) spiders.) }
$$

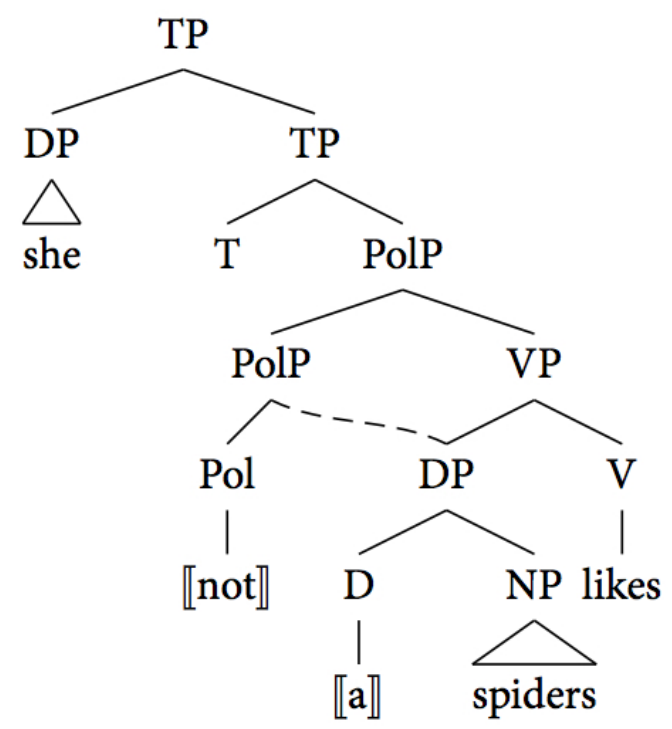

[Johnson 2010]

Johnson proposes that an Agree relation is established between the Pol-head and the determiner of the DP Pol merges with (like in his analysis of $w h$-movement, see above). This is where we diverge from his account. We propose that the Pol-head does not undergo Agree with the Dhead, but rather fusion under adjacency. We define fusion under adjacency as the morphological process whereby two syntactic terminals are spelled out by a single lexical item, provided these

\footnotetext{
${ }^{17}$ This is why the tree branch connecting PolP and DP is a dashed line: the merger of these two elements has no semantic import. See Johnson (2012) for details.
} 
two terminals are adjacent at the point when the syntactic structure is linearized. ${ }^{18}$ We have two reasons for proposing that negative indefinites involve fusion under adjacency rather than an Agreerelation. First, an Agree analysis of negative indefinites would predict the Probe (the head Pol) and the Goal (the head D) to be able to be spelled out simultaneously. Recall that in Tlingit the wh-form of D (= the Goal) and the Q-particle (= the Probe) overtly co-occur (cf. Cable $(2007,2010)$ ). A relevant example was given in (40), repeated here as (51):

[Aadóo yaagú sá] $]_{i}$ ysiteen $t_{i}$ ? whose boat $\mathrm{Q}$ you-saw 'Whose boat did you see?'

[Tlingit, Cable 2010:44 (67) as cited in Johnson 2012:539 (34)]

Negation and an agreeing D-head cannot be spelled out simultaneously, as illustrated in (52).
a. *John did not buy nothing.
(* under the single negation reading $)^{19}$
b. *John does not read no novels.
(* under the single negation reading)

An analysis in terms of fusion, on the other hand, correctly predicts sentential negation and negative indefinites to be in complementary distribution: the two syntactic terminals undergoing fusion are by definition realized as a single vocabulary item.

Secondly, negative indefinites often transparently consist of two components (negation + indefinite), as discussed at length in Sauerland (2000). For instance, in Mohawk the negative indefinite yahuhka 'nobody' consists of the sentential negation morpheme yah 'not' and the existential in-

\footnotetext{
${ }^{18}$ This process differs from the DM-version of fusion in that the latter takes two discrete terminal nodes that are sisters under a single category node and collapses them into a single terminal node (Halle and Marantz 1993:116). In our structures, Pol and D are not sisters under a single category node. Moreover, head movement from D to Pol is disallowed, so they cannot become sisters either.

${ }^{19}$ Note that this leaves room for an analysis of negative concord in terms of Agree rather than fusion. We will not explore this possibility here, but see Temmerman (2012:Ch.6) for some discussion.
} 
definite $u h k a(k)$ 'anybody' (data originally from Baker (1995:28-29) and Baker (1996:58-60)):

Shawatis yahuhka to-shako-ka-O.

John nobody NEG-AGR-see-STAT.

'John saw nobody.'

[Mohawk, Sauerland 2000:421 (10)]

Yah to-shako-ka-O uhka.

not NEG-AGR-see-STAT anybody

'He didn't see anybody.'

[Mohawk, Sauerland 2000:422 (15)]

Similarly, in Norwegian, the negative indefinite ingen 'no' consists of the negation ikke 'not' and the indefinite noen 'any' (cf. (55), data originally from Christensen (1986) as cited in Kayne (1998)), and in Dutch, the negative indefinite niets 'nothing' can be decomposed into the negation niet 'not' and the indefinite iets 'something', as shown in (56). ${ }^{20}$

a. Jon leser inger romaner.

John reads no novels

'John reads no novels.'

b. Jon leser ikke noen romaner.

John reads not any novels

'John does not read any novels.'

[Norwegian, Sauerland, 2000, 423, (17)-(18)]

a. Jan heeft niets gekocht.

John has nothing bought

'John has bought nothing.'

b. Dat is niet iets wat Jan gekocht heeft.

that is not something what John bought has

'That is not something John has bought.'

${ }^{20}$ Note that the two Dutch examples are not equivalent in meaning: in the second one, the existential quantifier gets a specific interpretation. See Huddlestone and de Swart (2014:155) for a similar example from Afrikaans and a discussion of the meaning difference. 
[Dutch]

Summing up, while we agree with Johnson that negative indefinites express in a single word information that is present in two distinct syntactic terminals and that this involves a multidominant derivation, we take the relation connecting the two pieces of the negative indefinite not to be syntactic in nature (Agree), but rather morphological (fusion under adjacency). ${ }^{21}$ In what follows, we show how this accounts for the two empirical generalizations laid out in the first half of the paper.

\subsection{Returning to the Scope Generalization}

\subsubsection{Three basic assumptions}

Before we present our account of the Scope Generalization, we need to clarify three basic assumptions. First, we follow the bulk of the literature on negation in assuming that clauses contain (at least) two scopal positions dedicated to negation (see among others Lasnik (1972), Robbers (1992), Zanuttini (1997), Oosthuizen (1998), Kemenade (2000), Barbiers (2002), Cormack and Smith (2002), Haegeman (2002), Holmberg (2003), Schwarz and Bhatt (2006), Biberauer (2008), Tubau (2008), van Craenenbroeck (2010)). More specifically, the clause structure we adopt is the

\footnotetext{
${ }^{21}$ Note that this means that we are introducing a third kind of configuration into Johnson's ontology: our analysis of negative indefinites is like his account of $w h$-movement in that it is the DP rather than the NP that is multiply dominated, but it is like his account of QR in that Pol and D are combined through fusion rather than Agree. As far as we are able to ascertain, adopting this type of analysis makes the correct predictions within Johnson's system (in addition to making the correct predictions outlined in the main text above). For example, it predicts that like QR, NEGshift is always covert. This aligns nicely with the observation that alleged instances of NEG-shift typically piggyback on independently attested movement operations, such as scrambling (Haegeman (1995)), object shift (Svenonius (2002)), or focus movement (Tubau (2008:136ff)).
} 
one in (57), with two Pol(arity)Ps, ${ }^{22}$ one dominating and one dominated by $\mathrm{TP}^{23}$

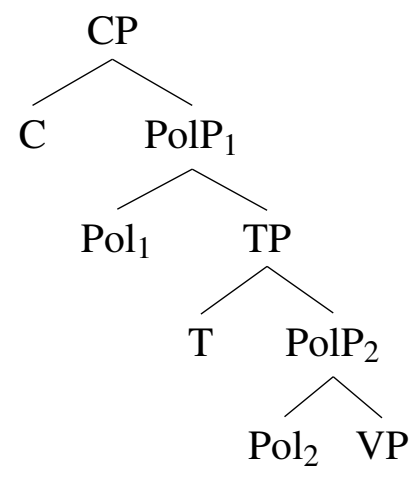

Secondly, we follow Zagona (1988), Lobeck (1995), Martin (1996), Johnson (2001), Merchant (2001), Aelbrecht (2009) and others in assuming that ellipsis requires a licensing head. That is, only particular heads with a certain feature specification (the licensors) can trigger PF-deletion of their complement. For VP-ellipsis in English, the licensing head is generally taken to be the inflectional head $\mathrm{T}$ when it is occupied by a finite auxiliary, a modal, or the infinitival marker to. This means that VP-ellipsis is actually ellipsis of the complement of T, i.e. in light of the structure in (57), ellipsis of the lower PolP:

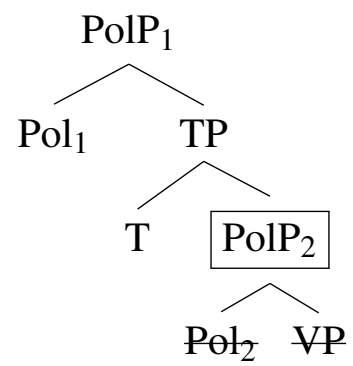

Thirdly, we adopt Fox and Pesetsky (2003, 2004)'s definition of ellipsis, given in (59):

${ }^{22} \mathrm{As}$ is customary, we assume that positive and negative polarity are expressed by a single functional projection. For discussion (and a variety of different names for this projection), see Pollock (1989), Laka (1990), Culicover (1991), Zanuttini (1997), Holmberg (2003), Zeijlstra (2004), Tubau (2008).

${ }^{23}$ The tree structure in (57) is a schematic representation in that it abstracts away from projections like $\nu \mathrm{P}$, AgrSP, AgrOP, AspP, ModP, AuxP, etc., and from the possibility of further splitting up TP and/or CP. 
Ellipsis [cf. Fox and Pesetsky (2003:21)]

Ellipsis of $\alpha$ involves (i) the non-pronunciation of any terminal element dominated by $\alpha$ and (ii) the deletion from the Ordering Table of all ordering statements referring to the terminal elements dominated by $\alpha$.

The notion of 'Ordering Table' is defined by Fox and Pesetsky (2003:16) as follows: “An Ordering Table receives the output of [the linearization algorithm] at various points as the derivation proceeds. The information that the Ordering Table receives from [Linearization] at any given stage is added to the information already present in the Ordering Table." What sets this definition apart from other 'deletion/non-insertion' approaches to ellipsis (Ross 1969, Sag 1976, Johnson 2001, Lasnik 2001, Merchant 2001) is that ellipsis not only affects the pronunciation of terminal elements, it also deletes the linearization statements referring to these terminals.

\subsubsection{Deriving the Scope Generalization}

Recall the Scope Generalization in (60) and the examples illustrating it in (61) and (62):

\section{The SCOPE GENERALIZATION}

A negative indefinite in object position cannot take scope outside of a VP-ellipsis site.

(61) Q: Who can offer no help?

A: * Quentin Tarantino can $\langle$ offer no help $\rangle$.

Q: Who can offer no help?

A: ${ }^{\%}$ Quentin Tarantino can $\langle$ effer no help $\rangle$.

In what follows, we first present the derivation of the sentence in (61). After merger of the VP (and arguably also Spell-Out and linearization, cf. Chomsky's (2000, 2001) Phase Theory), PolP 2 and $\mathrm{T}$ are merged. $\mathrm{T}$ attracts the subject to its specifier and triggers deletion of its complement, i.e. all linearization statements referring to terminal elements dominated by $\mathrm{PolP}_{2}$ are removed from the ordering table. This point in the derivation is shown in (63), and the linearization of the elided 
$\mathrm{PolP}_{2}$ is given in (64):

(63)

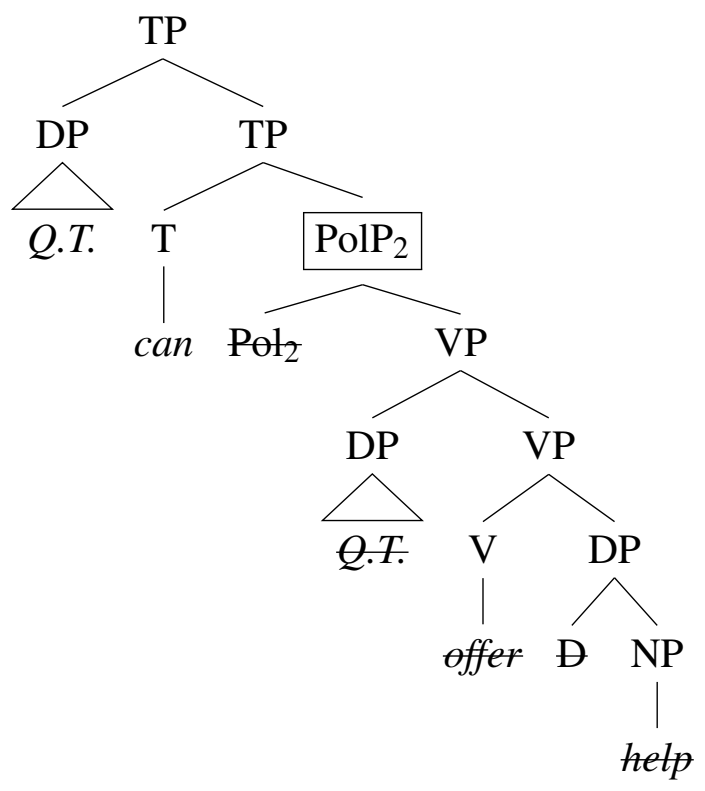

(64) The linearization of $\mathrm{PolP}_{2}$ is:

$$
\left\{\begin{array}{lll}
\text { Pol }_{2}<\text { Q.T. } & \text { Q.T. }<\text { offer } & \text { offer }<\text { D } \quad \text { D }<\text { help } \\
\text { Pol }_{2}<\text { offer } & \text { Q.T. }<\mathrm{D} \quad \text { offer }<\text { help } \\
\mathrm{Pol}_{2}<\mathrm{D} & \text { Q.T. }<\text { help } & \\
\mathrm{Pol}_{2}<\text { help } &
\end{array}\right\}
$$

Given that in the example we are trying to derive (i.e. (61)), negation outscopes the modal in T, it is the highest of the two PolPs that is used to indicate the scope of the negative indefinite. Accordingly, in the next step of the derivation $\mathrm{Pol}_{1}$ merges with DP: 


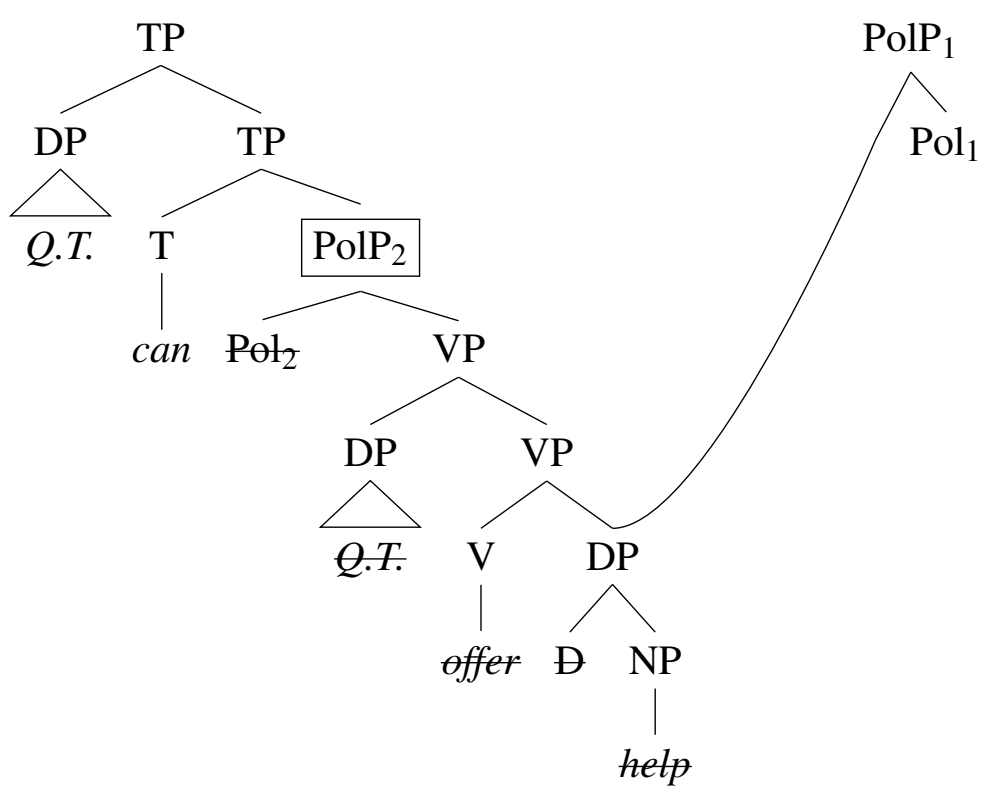

This is the point in the derivation where $\mathrm{Pol}_{1}$ and $\mathrm{D}$ would normally undergo fusion to form the lexical item no (i.e. right before the merger of $\mathrm{PolP}_{1}$ and TP, compare with Johnson's account in (45) above). As it turns out, however, D has already been elided, which means there is nothing to fuse with: fusion is bled and $\mathrm{PolP}_{1}$ can only be spelled out as an independent lexical item, i.e. as not/n't. In other words, the derivation just sketched is spelled out as (66); the example in (67) can_—in the intended reading__ simply not be derived by our system.

*Quentin Tarantino can $\langle$ effer no help $\rangle$.

$(* \neg>\diamond)$

Now let's turn to the other scope reading, i.e. the grammatical example in (62), repeated below.

Q: Who can offer no help?

A: ${ }^{\%}$ Quentin Tarantino can $\langle$ offer no help $\rangle$.

For those speakers who allow the modal can to outscope negation, this reading is also available in VPE-contexts. Given that in this case negation scopes below $\mathrm{T}$, it is $\mathrm{Pol}_{2}$ that merges with the 
direct object. This is shown in (69).

(69)

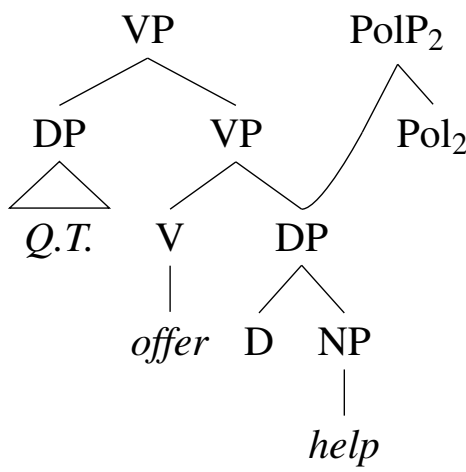

At this point, the morphological requirements of $\mathrm{Pol}_{2}$ and $\mathrm{D}$ trigger (cyclic) linearization. The result is shown in (70) and (71):

(70) The linearization of VP:

$$
\left\{\begin{array}{ll}
\text { Q.T. }<\text { offer } & \text { offer }<\text { D } \quad \text { D }<\text { help } \\
\text { Q.T. }<\text { D } & \text { offer }<\text { help } \\
\text { Q.T. }<\text { help } &
\end{array}\right\}
$$

(71) The linearization of $\mathrm{Pol}_{2}$ :

$$
\left\{\begin{array}{l}
\mathrm{Pol}_{2}<\mathrm{D} \quad \mathrm{D}<\text { help } \\
\mathrm{Pol}_{2}<\text { help }
\end{array}\right\}
$$

Given the definition of adjacency in (47)-(48), $\mathrm{Pol}_{2}$ and D are adjacent. The linearization algorithm has placed no node in between them, which means they can undergo fusion under adjacency into no: 
(72) The linearization of VP:

$$
\left\{\begin{array}{ll}
\text { Q.T. }<\text { offer } & \text { offer }<\text { no } \quad \text { no }<\text { help } \\
\text { Q.T. }<\text { no } & \text { offer }<\text { help } \\
\text { Q.T. }<\text { help } &
\end{array}\right\}
$$

(73) The linearization of $\mathrm{Pol}_{2}:\{$ no $<$ help $\}$

In the next step of the derivation, $\mathrm{VP}$ and $\mathrm{PolP}_{2}$ are merged together, and after that, $\mathrm{T}$ is merged. It attracts the subject to its specifier and triggers deletion of its complement. This point in the derivation is shown in (74), and the linearization of the elided $\mathrm{PolP}_{2}$ in (75):

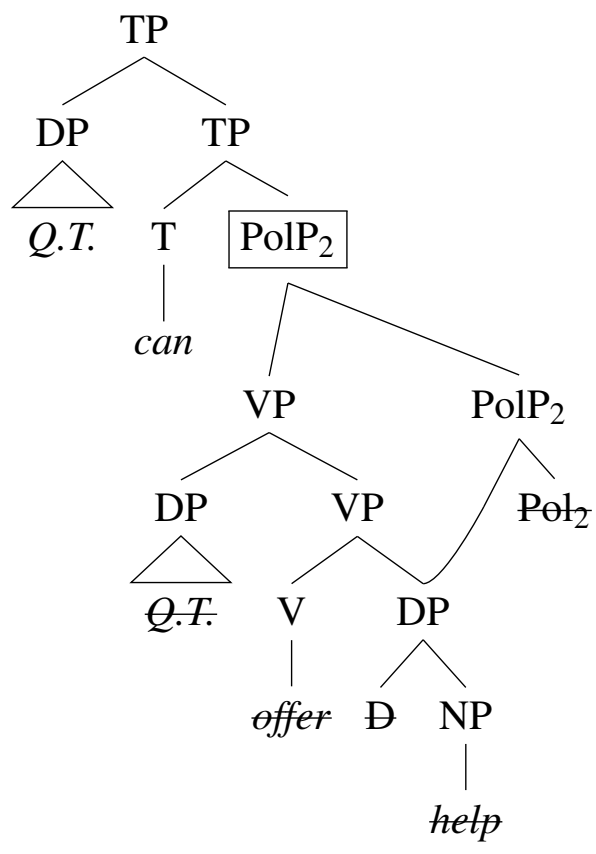


(75) The linearization of $\mathrm{PolP}_{2}$ :

$$
\left\{\begin{array}{ll}
\text { Q.T. }<\text { offer } & \text { effer }<\mathrm{D} \quad \text { no }<\text { help } \\
\text { Q.T. }<\text { no } & \text { offer }<\text { help } \\
\text { Q.T. }<\text { help } &
\end{array}\right\}
$$

Finally, the rest of the structure is merged $\left(\mathrm{Pol}_{1}, \mathrm{C}\right.$, etc.) and the derivation is spelled out as (76):

$$
{ }^{\%} \text { Quentin Tarantino can }\langle\text { өffer no help }\rangle .
$$

What the combination of these two derivations shows, is that is is the timing of ellipsis vis-à-vis fusion that plays a crucial role in determining whether or not negative indefinites can sit inside an ellipsis site. If fusion takes place prior to ellipsis (i.e. if D merges with $\mathrm{Pol}_{2}$ ), the derivation converges and the VP-ellipsis site can contain an object negative indefinite. If this fusion operation tries to target a structure that has already been elided (i.e. if $\mathrm{D}$ merges with $\mathrm{Pol}_{1}$ ), the target for fusion is gone and the operation is bled. The net result is that a negative indefinite cannot take scope outside of a VP-ellipsis site, i.e. we have derived the Scope Generalization.

Before turning to the any/no-Generalization, however, let us consider an alternative derivation of the example in (61) (repeated below as (77)), one that at first glance has the unwanted potential of ruling in the inverse scope reading. ${ }^{24}$

Q: Who can offer no help?

A: * Quentin Tarantino can $\langle$ effer no help $\rangle$.

The alternative account essentially amounts to combining elements from the two derivations sketched above: like in the derivation in (69), the polarity head is introduced early in the derivation, i.e. before VP-ellipsis takes place, but like the structure in (65), polarity is integrated into the clausal

\footnotetext{
${ }^{24}$ Many thanks to a Syntax-reviewer for suggesting this alternative.
} 
spine only after TP has merged. More specifically, let's assume that after the VP is finished, the direct object is merged with $\mathrm{Pol}_{1}$ (or, that there is parallel merge of the object DP with $\mathrm{V}$ and $\mathrm{Pol}_{1}$ ). The resulting structure is (78):

(78)

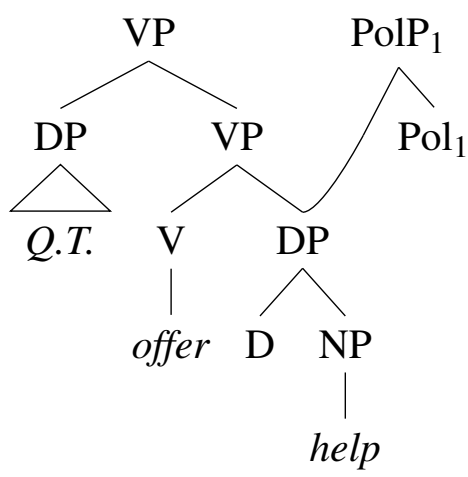

At this point in the derivation, $\mathrm{Pol}_{1}$ and $\mathrm{D}$ can undergo fusion under adjacency to form the negative determiner no, as the linearization algorithm has placed nothing in between the two elements. Next, PolP 2 and TP are merged, T attracts the subject to its specifier, and triggers VP-ellipsis. This is shown in (79).

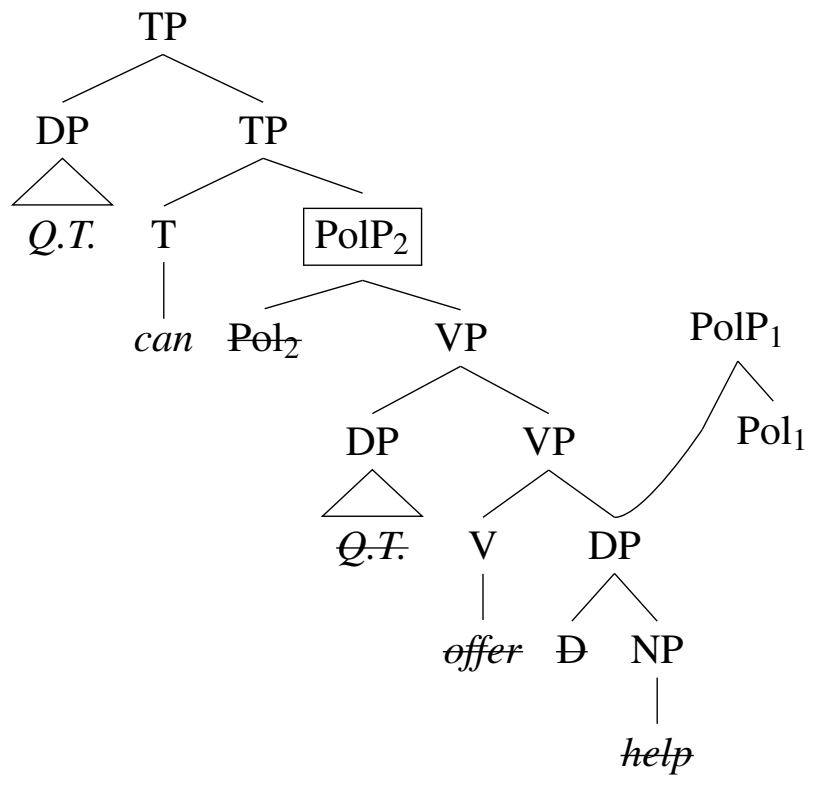


Note that is the exact same tree as (65), except that it has been arrived at through a different derivation. In particular, the timing of the merger between $\mathrm{Pol}_{1}$ and $\mathrm{D}$ and the application of VP-ellipsis has been reversed: the former now precedes the latter. Given that it was precisely that timing that played a crucial role in our analysis of the Scope Generalization, the alternative derivation sketched in (78)-(79) is potentially damaging. We will present two possible responses to this challenge, without choosing between the two. The first will remain very close to the proposal of the Scope Generalization outlined in this section and will suggest a way of ruling out the derivational step shown in (78), i.e. the 'early merger' of $\mathrm{Pol}_{1}$. The second option will be to allow the derivation in (78)-(79), but to make a slight change to Johnson (2012)'s spell-out algorithm so as to be able to retain the timing aspect of our account. ${ }^{25}$

The first approach one could take towards ruling out the alternative derivation in (78)-(79) would be to block $\mathrm{Pol}_{1}$ from being merged into the derivation at the stage shown in (78). In particular, assume that the merger of the functional heads in the clausal spine has to follow the functional sequence familiar from cartographic work (e.g. Cinque (1999)). This can be implemented as a requirement on the operation Select: it can only select the $\mathrm{Pol}_{1}$-head from the Numeration after it has first selected $\mathrm{T}$ (which itself is dependent on the selection of $\mathrm{Pol}_{2}$, etc.). Indeed, if access to the lexicon proceeds not in bulk, but via lexical arrays or subnumerations as proposed by Chomsky (2000), the $\mathrm{Pol}_{1}$-head would simply not be available for selection at the stage of the derivation illustrated in (78). At any rate, whatever the precise mechanism driving the restriction, the result would be that $\mathrm{Pol}_{1}$ cannot be introduced into the derivation until after $\mathrm{T}$ is merged, which means that our analysis of the Scope Generalization as we have presented it above can be upheld without changes.

\footnotetext{
${ }^{25}$ Note that—contrary to what a reviewer suggested—Chomsky (1995)'s Extension Condition cannot help us choose between the two derivations. As argued in detail by de Vries $(2009,2013)$, the type of structure-building operation used here (called external remerge by De Vries) always has at least one root node as its input (regardless of when Pol and D are merged) and as such can be argued to extend the derivation. See the papers cited for details.
} 
A second approach towards the analysis in (78)-(79) would be to allow these derivations, but to tweak the linearization mechanism that we have been assuming so far. Recall that we have followed Johnson (2012) in assuming that what drives linearization during the derivation (apart from phasal spell-out) are the morphological requirements of the heads about to undergo fusion ( $\forall$ and D in Johnson (2012)'s analysis of QR, Pol and D in our account). In Johnson (2001:545)'s phrasing, the fact that $\forall$ in English can only be expressed morphologically in a single lexical item that also expresses D/the "has the effect of forcing fusion to occur before QR builds the offending structure. Because fusion requires of the terms to be fused that they be adjacent, this will also require that the linearization algorithm be run on structures formed before QR has applied.” On closer inspection, however, this approach has a number of downsides. Most notably, there's a clear lookahead flavor to it: $\forall$ seems to have to 'know beforehand' that it runs the risk of being unpronounced in order for it to force the derivation to undergo linearization prematurely. A second reason to be suspicious is that it seems unlikely for the morphological properties of individual lexical items to control central properties in the flow of the syntactic derivation. A possible alternative would be to adopt the multiple spell-out model of Uriagereka (1999). A central ingredient of that proposal is that complex specifiers or adjuncts need to be spelled out (and hence linearized) before they are merged into the clausal spine. Applying that to the derivation in (78)-(79), it becomes clear that at the point in the derivation shown in in (78), there is no trigger to linearize PolP $\mathrm{P}_{1}$ : it is not a phase, and it is not yet integrated into the clausal spine. However, as long as $\mathrm{PolP}_{1}$ is not linearized, $\mathrm{Pol}_{1}$ and D are not adjacent and fusion cannot take place. It is only at the stage depicted in (79), right before $\mathrm{PolP}_{1}$ gets integrated into the clausal spine, that Uriagereka-style multiple spell-out forces PolP 1 to be linearized. However, at this point, D has already been elided and fusion is no longer an option.

Summing up, we have discussed two approaches towards dealing with the alternative derivation sketched in (78)-(79). As pointed out above, we will not choose between them here, as we believe both to be viable options. Moreover, both retain the central intuition of our analysis of the Scope Generalization, namely the fact that this empirical generalization finds its explanation in the timing of the various components of the derivation (merger, linearization, ellipsis). In the next subsection 
we direct our attention to the any/no-generalization.

\subsection{Deriving the any/no-Generalization}

The any/no-Generalization is repeated in (80) and some relevant examples are given in (81) and (82):

THE ANY/NO GENERALIZATION

While no can antecede the ellipsis of any in verbal ellipsis, the reverse configuration is disallowed.

(81) Martin Scorsese liked no movie and Quentin Tarantino didn't $\langle$ like any movie $\rangle$ either.

(82) Who didn't like any movie?

* Quentin Tarantino did 〈like no-movie $\rangle$.

It should come as no surprise that we want to try and account for these facts with the same mechanisms that were responsible for the Scope Generalization, i.e. the question of whether the determiner of the direct object is merged with the higher or the lower of the two Pol-heads. In fact, the examples in (81) and (82) already follow straightforwardly from our account. Let us see why this is the case.

As pointed out above, we follow Fox (2000) in assuming that an ellipsis site has to be parallel to its antecedent. As was already foreshadowed in footnote 13, however, the precise definition of Parallelism we have in mind is more specific than the one given in (26), repeated here as (83).

Parallelism (a consequence of)

In an ellipsis construction, the scopal relationship among the elements in the antecedent must be identical to the scopal relationship among the parallel elements in the ellipsis site. [Fox 2000:32] 
In particular, we follow Fiengo and May (1994), Fox (2000:86, 117), and Fox and Lasnik (2003) in adopting the view that ellipsis parallelism requires not just scopal but rather structural isomorphism between antecedent and ellipsis site (see also Merchant (2013b) for a related view). The former entails the latter, but not vice versa. This is particularly clear in Fox and Lasnik (2003)'s sluicing analysis: they not only require that the sluiced wh-phrase and its correlate in the antecedent clause have the same scope, but also that each intermediate position of the two matches up. In what follows, we adhere to this more rigid implementation of Parallelism, i.e. when we use the term 'Parallelism' in the discussion below, this should be taken to mean 'Structural Parallelism'. With respect to the data that we are concerned with (negative indefinites under verbal ellipsis), we more specifically take this to mean that it has to be the same polarity head (i.e. the same structural position) that is activated in both the ellipsis-containing clause and the antecedent clause (either PolP $_{1}$ in both or $\mathrm{PolP}_{2}$ in both).

With this in mind, let us turn to (81). The fact that the negation $n^{\prime} t$ in the second clause occurs outside of the ellipsis site indicates that this is the spell-out of $\mathrm{Pol}_{1}$. Parallelism requires that this same polarity phrase be activated in the first clause as well. We have seen that in a nonelliptical clause (barring any other scope-taking elements), a negative indefinite can be the result of fusion with either polarity head: thus, Parallelism can be respected in this case, and the example is correctly ruled in. Things are different, though, in the second example, i.e. in (82). Cormack and Smith (2002) have argued that the contracted negation $n$ 't is invariably the spell-out of the higher polarity head. This means that in the antecedent clause, it is $\mathrm{Pol}_{1}$ that is activated. Parallelism now requires that the same be true of the ellipsis sentence, but this raises a problem. Given that VP-ellipsis bleeds fusion between the high Pol-head and the determiner of the direct object (see the previous section), the elided VP cannot contain a negative indefinite that is the result of fusion between $\mathrm{Pol}_{1}$ and D. Parallelism (which requires that $\mathrm{Pol}_{1}$ be activated) cannot be respected here, and the example is (correctly) ruled out.

Summing up, our account of the any/no-Generalization is essentially the same as that of the Scope Generalization. The presence of any in the antecedent clause forces the negative indefinite to 
take scope outside of the ellipsis site. This is, however, impossible, because the negative indefinite in a verbal ellipsis site cannot be the result of fusion between the D-head and the high Pol-head, given that ellipsis bleeds this fusion operation. As a result, Parallelism is violated and the example is ruled out.

It should be clear, though, that the pair in (81)-(82) does not exhaust the range of possible configurations we need to look at in the context of the any/no-Generalization. In particular, consider the following example (provided to us by a reviewer, and with the judgment confirmed by our informants):

John did not read any book yesterday.

* Bill did $\langle$ read no book $\rangle$ today. ${ }^{26}$

In this case, we are not using the contracted negation $n$ 't, but rather its full form not. Following standard practice, we assume this form can be merged in either the low or the high polarity position. This means that it should in principle be possible to construct a converging derivation for this example: the not in the antecedent clause is the spell-out of $\mathrm{Pol}_{2}$, and the negative indefinite in the ellipsis site arises as the result of a fusion process between $\mathrm{Pol}_{2}$ and the determiner of the direct object, obeying Parallelism. Given that this fusion operation is wholly contained inside the ellipsis site, it is not bled by the application of ellipsis and the example should be fine. The fact that it isn't, we believe, is due to the nature of the two polarity phrases. So far we have presented the two PolPs as being fully interchangeable, distinguished only by their position in the clausal functional hierarchy. Let us assume, however, that this difference in structural height corresponds to a more contentful distinction as well. In particular, assume that the high PolP expresses propositional negation, and the lower one predicate negation. To make this more concrete, consider the example in (85) and its two possible logical interpretations in (86) (the example is from Butler (2003:983)):

\footnotetext{
${ }^{26}$ Note that for some of our informants the string Bill did today has a grammatical parse in this context, with the meaning 'Bill did read a book today'. We ignore this reading in what follows.
} 
My hoover isn't working.
a. $\neg[$ my hoover is working]
b. my hoover is $[\neg$ working $]$

The formula in (86a) "denies a proposition, while [(86b)] affirmatively ascribes a negated predicate to a subject" (Butler (2003:983)). In the absence of other scope-bearing material in the clause, the two interpretations are truth-conditionally equivalent, but what we want to propose is that the default option is the higher, propositional negation. More specifically, the default Merge position for $n o t$ is $\mathrm{Pol}_{1} \cdot{ }^{27}$ This not only explains why the example in (84) is not well-formed, it also makes a clear prediction: if we can force a low reading for not in the antecedent, a switch from any in the antecedent to no in the ellipsis site should be grammatical. Consider in that respect the following variation on the example in (84):

[CONTEXT: John and Bill are being very uncooperative in class, and moreover, John seems to be influenced by Bill's (bad) behaviour.]

John will probably NOT read any book today, just like Bill did yesterday.

${ }^{27}$ A reviewer points out that this proposal for English differs from the one put forward for German by Schwarz (2004) and Schwarz and Bhatt (2006). They argue that the default position for ordinary sentential negation nicht 'not' corresponds to what we have been calling the low PolP, and that only in certain syntactic environments, namely NPIlicensing contexts, a high position (what we would consider to be the high PolP) becomes available. Thus, based on Schwarz (2004) and Schwarz and Bhatt (2006), it would seem that in German there is a preference for sentential negation to target the lower of the two PolPs. See Zeijlstra (2012), however, for a criticism of the Schwarz/Bhatt-approach and a reanalysis of their basic facts. Moreover, note that Cormack and Smith (2002) have argued on independent grounds that the English contracted negation n't occupies the high polarity head. As this element is by no means limited to specific syntactic environments, it is clear that the high PolP in English is not restricted in the same way as Schwarz and Bhatt claim it is in German. Given that English is the main focus of this paper, we leave this potentially interesting point of cross-linguistic variation open here. 
Our informants confirm that this example is not only grammatical, it also has an ellipsis site with a negative interpretation, unlike the one in (84). A similar example is given in (88).

[CONTEXT: There's an eating contest and both John and Mary want to end last in the contest. Peter and Julie are discussing this.]

Peter: So can John forfeit the game?

Julie: Well, he COULD not eat anything, I guess.

Peter: But then, Mary could too.

The problem with these kinds of examples, though, is that there is no way of telling if the ellipsis site contains a (fused) negative indefinite or an NPI licensed by $\mathrm{Pol}_{2}$. The ellipsis site in (87) could have either of the two underlying structures in (89), and similarly for (88) and (90).

a. John will probably NOT read any book today, just like Bill did /not read any boek〉 yesterday.

b. John will probably NOT read any book today, just like Bill did /read no book〉 yesterday.
a. But then, Mary could $\langle$ not eat anything $\rangle$ too.
b. But then, Mary could 〈eat nothing ) too.

Summing up, the account we have provided for the Scope Generalization carries over to the any/noGeneralization, at least in so far as the clearest examples are concerned (i.e. data such as those in (81)-(82)). For the more complicated examples such as the one in (84), we have more tentatively suggested that there is a preference for sentential negation to target the higher of the two PolPs. ${ }^{28}$ This preference can be overridden given the right context, but at that point it becomes impossible

\footnotetext{
${ }^{28}$ Note that this preference might also be at play in examples where no antecedes the ellipsis of $n o$, see section 2.3 . In particular, a reviewer provides the example in (i) and points out that for him/her the second sentence can only get a positive interpretation ('Steve scored at least one goal today').
} 
to determine whether the ellipsis site contains a negative indefinite or a low negation combined with an NPI in object position.

\section{Summary and Conclusions}

This paper has focused on the scopal patterns of English negative indefinites in VP-ellipsis contexts. We have presented the following two empirical generalizations:

THE ANY/NO GENERALIZATION

While no can antecede the ellipsis of any in verbal ellipsis, the reverse configuration is disallowed.

\section{The SCOPE Generalization}

A negative indefinite in object position cannot take scope outside of a VP-ellipsis site.

We have argued that negative indefinites do not undergo QR or Agree/feature checking. Rather, they decompose into two independent elements, sentential negation (Pol) and an indefinite determiner (D). Their formation is the result of a morphological process, fusion under adjacency. The

John scored no goals yesterday.

? Steve did today.

Most of our informants share this judgement. All of them, however, agree that the example vastly improves (with the relevant negative reading of 'Steve scored no goals yesterday') when presented in the following context: "John and Steve are both playing a soccer video game, and they have certain achievements that they need to unlock. One is to go through a whole soccer match without scoring any goals. John unlocked that achievement yesterday, Steve today." So once again, forcing the negation to be interpreted low improves the acceptability of the examples.

As for the examples we presented in section 2.3 ((12) and (13) in particular), it is worth pointing out that both of them contain additional operator material (wh-movement and subject focus respectively). If Butler (2003) is right in proposing that there is a tight connection between the high PolP and FocP (he goes so far as to equate them), then the presence of operator material in FocP might be what allows/triggers the low PolP to be activated in these examples.

Finally, note that the absence of no in the ellipsis sites in (7) (see also note 2) is of a different nature: having a negative indefinite in the ellipsis sites here would simply render the examples pragmatically highly infelicitous. 
locality/adjacency required for fusion of the negation and the indefinite comes about under multidominance (i.e. it is established through remerge). When ellipsis, a PF-process, precedes this instance of fusion, it can bleed it. This, we have argued, is what blocks the occurrence of highscoping negative indefinites inside VP-ellipsis sites, and what prevents not... any from anteceding no in VP-ellipsis in most contexts.

\section{References}

Aelbrecht, Lobke. 2009. You have the right to remain silent: The syntactic licensing of ellipsis. Doctoral Dissertation, Catholic University of Brussels.

Baker, Mark. 1995. On the absence of certain quantifiers in Mohawk. In Quantification in natural languages, ed. E. Bach et al., 21-58. Dordrecht: Kluwer.

Baker, Mark. 1996. The polysynthesis parameter. Oxford: Oxford University Press.

Barbiers, Sjef. 2002. Microvariation in negation in varieties of Dutch. In Syntactic microvariation, ed. S. Barbiers, L. Cornips, and S. van der Kleij, 13-40. Amsterdam: Meertens Instituut.

Bech, Gunnar. 1955/57. Studien über das deutsche Verbum infinitum. Unveränderte Auflage, Niemeyer Verlag, Tübingen, 1983.

Beghelli, Filippo. 1993. A minimalist approach to quantifier scope. In Proceedings of the North East Linguistic Society 23, ed. A.J. Schafer, 65-80. University of Ottowa: GLSA.

Biberauer, Theresa. 2008. Doubling and omission: insights from Afrikaans negation. In Microvariation in syntactic doubling, ed. Sjef Barbiers, Margreet van der Ham, Olaf Koeneman, and Marika Lekakou, 103-140. Bingley: Emerald.

Butler, Johny. 2003. A minimalist treatment of modality. Lingua 113:967-996.

Cable, Seth. 2007. The grammar of Q: Q-particles and the nature of wh-fronting, as revealed by the wh questions of Tlingit. Doctoral Dissertation, MIT. 
Cable, Seth. 2010. The Grammar of Q: Q-Particles, Wh-Movement and Pied-Piping. Oxford: Oxford University Press.

Chomsky, Noam. 1995. The minimalist program. Cambridge, Massachusetts: MIT Press.

Chomsky, Noam. 2000. Minimalist inquiries: The framework. In Step by step: Essays on minimalist syntax in honor of Howard Lasnik, ed. R. Martin, D. Michaels, and J. Uriagereka, 89-155. Cambridge, MA: MIT Press.

Chomsky, Noam. 2001. Derivation by phase. In Ken Hale: A life in language, ed. M. Kenstowicz, 1-54. Cambridge, MA: MIT Press.

Christensen, Kristi Koch. 1986. Norwegian ingen: A case of post-syntactic lexicalization. In Scandinavian syntax, ed. O. Dahl and A. Holmberg, 24-35. Stockholm: Institute of Linguistics, University of Stockholm.

Cinque, Guglielmo. 1999. Adverbs and functional heads: a cross-linguistic perspective. New York: Oxford University Press.

Cormack, Annabel, and Neil Smith. 2002. Modals and negation in English. In Modality and its interaction with the verbal system, ed. Sjef Barbiers, Frits Beukema, and Wim van der Wurff, 133-163. Amsterdam: John Benjamins.

van Craenenbroeck, Jeroen. 2010. The syntax of ellipsis: Evidence from Dutch dialects. Oxford: Oxford University Press.

Culicover, Peter. 1991. Topicalisation, inversion and complementizers in English. In Going Romance and beyond, ed. D. Delfitto, M. Everaert, A. Evans, and F. Stuurman, 1-43. Utrecht: University of Utrecht.

Dahl, Östen. 1993. Negation. In Syntax: An international handbook, ed. Joachim Jacobs, Armin von Stechow, Wolfgang Sternefeld, and Theo Vennemann, 914-923. Berlin: De Gruyter. 
Engdahl, Elisabet. 1980. The syntax and semantics of questions in Swedish. Doctoral Dissertation, University of Massachusetts.

Engdahl, Elisabet. 1986. Constituent questions. Dordrecht: D. Reidel Publishing Company.

Fiengo, Robert, and Robert May. 1994. Indices and identity. Cambridge, MA: MIT Press.

von Fintel, Kai, and Sabine Iatridou. 2003. Epistemic containment. Linguistic Inquiry 34:173-198.

Fox, Danny. 2000. Economy and semantic interpretation. Cambridge, MA: MIT Press.

Fox, Danny. 2003. On logical form. In Minimalist syntax, ed. R. Hendrick, 82-123. Oxford: Blackwell.

Fox, Danny, and Howard Lasnik. 2003. Successive-cyclic movement and island repair: the difference between Sluicing and VP-ellipsis. Linguistic Inquiry 34:143-154.

Fox, Danny, and David Pesetsky. 2003. Cyclic linearization and the typology of movement. Lecture notes, MIT. Handout available online at: http://web.mit.edu/linguistics/people/ faculty/fox/July_19_handout.pdf.

Fox, Danny, and David Pesetsky. 2004. Cyclic linearization and its interaction with other aspects of the grammar: a reply. In Theoretical Linguistics (Special issue on object shift in Scandinavian), ed. Katalin É. Kiss, volume 31:1-2, 235-262.

Geurts, Bart. 1996. On no. Journal of Semantics 13:67-86.

Giannakidou, Anastasia. 1997. The landscape of polarity items. Doctoral Dissertation, University of Groningen.

Giannakidou, Anastasia. 1998. Polarity sensitivity as (non)veridicality. Amsterdam: John Benjamins.

Ha, Seungwan. 2007. Ellipsis, Right Node Raising, and Across-The-Board constructions. Doctoral Dissertation, Boston University. 
Haegeman, Liliane. 1995. The syntax of negation. Cambridge: Cambridge University Press.

Haegeman, Liliane. 2002. West Flemish negation and the derivation of SOV order in West Germanic. Nordic Journal of Linguistics 25:154-189.

Haegeman, Liliane, and Terje Lohndahl. 2010. Negative concord and (multiple) Agree: A case study of West Flemish. Linguistic Inquiry 41:181-211.

Haegeman, Liliane, and Raffaella Zanuttini. 1991. Negative heads and the Neg Criterion. The Linguistic Review 8:233-251.

Haegeman, Liliane, and Raffaella Zanuttini. 1996. Negative concord in West-Flemish. In Parameters and functional heads. Essays in comparative syntax, ed. Adriana Belletti and Luigi Rizzi, 117-179. Oxford: Oxford University Press.

Hagstrom, Paul. 1998. Decomposing questions. Doctoral Dissertation, MIT.

Halle, Morris, and Alec Marantz. 1993. Distributed Morphology and the pieces of inflection. In The view from building 20, ed. Kenneth Hale and Samuel Jay Keyser, 111-176. Cambridge, MA: MIT Press.

Hardt, Daniel. 1993. Verb Phrase Ellipsis: Form, meaning and processing. Doctoral Dissertation, University of Pennsylvania.

Holmberg, Anders. 2003. Yes/no questions and the relation between tense and polarity in English and Finnish. In Linguistic Variation Yearbook 2003, ed. P. Pica and J. Rooryck. Amsterdam: John Benjamins.

Huddlestone, K., and H. de Swart. 2014. A bidirectional Optimality Theoretic analysis of multiple negative indefinites in Afrikaans. Stellenbosch Papers in Linguistics 43:137-164.

Iatridou, Sabine, and Ivy Sichel. 2011. Negative DPs, A-movement, and scope diminishment. Linguistic Inquiry 42:595-629. 
Iatridou, Sabine, and Hedde Zeijlstra. 2010. On the scopal interaction of negation and deontic modals. In Logic, language, and meaning: 17th Amsterdam Colloquium Revised Selected Papers, ed. Maria Aloni, Harald Bastiaanse, Tikitu de Jager, and Katrin Schulz, 315-324. Berlin: Springer.

Jackendoff, Ray. 1972. Semantic interpretation in generative grammar. Cambridge, MA: MIT Press.

Jacobs, Joachim. 1980. Lexical decomposition in Montague Grammar. Theoretical Linguistics $7: 121-136$.

Johnson, Kyle. 2001. What vp ellipsis can do, what it can't, but not why. In The handbook of contemporary syntactic theory, ed. Mark Baltin and Chris Collins, 439-479. Oxford: Blackwell.

Johnson, Kyle. 2010. Negative indefinites. E-mail correspondence with Karen De Clercq, GIST/Ghent University.

Johnson, Kyle. 2012. Towards deriving differences in how Wh Movement and QR are pronounced. Lingua 122:529-553.

Kamp, Hans. 1973. Free choice permission. In Proceedings of the Aristotelian Society, N.S., volume 74, 57-74.

Kayne, Richard. 1998. Overt vs. covert movement. Syntax 1:128-191.

Kemenade, Ans Van. 2000. Jespersen's cycle revisited. In Diachronic syntax, ed. S. Pintzuk, G. Tsoulas, and A. Warner, 51-74. Oxford: Oxford University Press.

Kennedy, Chris. 1997. Antecedent-contained deletion and the syntax of quantification. Linguistic Inquiry 28:662-688.

Kishimoto, Hideki. 2005. Wh-in-situ and movement in Sinhala questions. Natural Language and Linguistic Theory 23:1-51. 
Kitahara, Hisatsugu. 1996. Raising quantifiers without quantifier raising. In Minimalist ideas: Syntactic studies in the minimalist framework, ed. W. Abraham et al., 189-198. Amsterdam: John Benjamins.

Klima, Edward S. 1964. Negation in English. In The structure of Language, ed. Jerry Fodor and Jerrold Katz. Prentice Hall, Englewood Cliffs.

Ladusaw, William A. 1979. Polarity sensitivity as inherent scope relations. Doctoral Dissertation, University of Massachusetts at Amherst, Amherst, MA.

Ladusaw, William A. 1992. Expressing negation. In Proceedings of SALT II, Ohio State Working Papers in Linguistics, ed. Chris Barker and David Dowty, volume 40, 237-259.

Laka, Itziar. 1990. Negation in syntax. On the nature of functional categories and projections. Doctoral Dissertation, MIT.

Lasnik, Howard. 1972. Analyses of negation in English. Doctoral Dissertation, MIT.

Lasnik, Howard. 2001. When can you save a structure by destroying it? In Proceedings of the North East Linguistic Society 31, ed. M. Kim and U. Strauss, 301-320. Amherst, MA: GLSA.

Lobeck, Anne. 1995. Ellipsis: Functional heads, licensing and identification. Oxford: Oxford University Press.

Martin, Roger. 1996. A minimalist theory of PRO and control. Doctoral Dissertation, University of Connecticut, Storrs.

Merchant, Jason. 2001. The syntax of silence: Sluicing, islands and the theory of ellipsis. Oxford: Oxford University Press.

Merchant, Jason. 2013a. Polarity items under ellipsis. In Diagnosing syntax, ed. Lisa Cheng and Norbert Corver, 441-462. Oxford: Oxford University Press.

Merchant, Jason. 2013b. Voice and ellipsis. Linguistic Inquiry 44:77-108. 
Oosthuizen, J. 1998. The final 'nie' in Afrikaans negative sentences. Stellenbosch Papers in Linguistics 31:61-93.

Penka, Doris. 2011. Negative indefinites. Oxford: Oxford University Press.

Penka, Doris, and Hedde Zeijlstra. 2010. Negation and polarity: An introduction. Natural Language and Linguistic Theory 28:771-786.

Pollock, Jean-Yves. 1989. Verb movement, Universal Grammar, and the structure of IP. Linguistic Inquiry 20:365-424.

Quine, Willard Van Orman. 1960. Word and object. Cambridge, MA: Technology Press of the Massachusetts Institute of Technology.

Reinhart, Tanya. 1997. Quantifier scope: How labor is divided between QR and choice functions. Linguistics and Philosophy 20:335-397.

Reinhart, Tanya. 1998. Wh-in-situ in the framework of the Minimalist Program. Natural Language Semantics 6.

Robbers, Karin. 1992. Properties of negation in Afrikaans and Italian. In Linguistics in the Netherlands, ed. R. Bok-Bennema and R. van Hout, 223-234. Amsterdam: John Benjamins.

Rochemont, Michael. 1978. A theory of stylistic rules in English. Doctoral Dissertation, University of Massachusetts at Amherst, Amherst, MA.

Ross, John Robert. 1969. Guess who? In Papers from the fifth regional meeting of the Chicago Linguistic Society, ed. R. Binnick, A. Davidson, G. Green, and J. Morgan, 252-286. Chicago: Chicago Linguistic Society.

Rullmann, Hotze. 1995. Geen eenheid. Tabu 25:195-198.

Sag, Ivan. 1976. Deletion and Logical Form. Doctoral Dissertation, MIT. 
Sauerland, Uli. 2000. No 'no': On the crosslinguistic absence of a determiner 'no'. In Proceedings of the Tsukuba Workshop on Determiners and Quantification, ed. Uli Sauerland, 415-444. Tsukuba (J): Tsukuba University.

Schwarz, Bernhard. 2004. How to rescue negative polarity items. Ms, University of Texas at Austin.

Schwarz, Bernhard, and Rajesh Bhatt. 2006. Light negation and polarity. In Cross linguistic research in syntax and semantics: Negation, tense, and clausal architecture, ed. R. Zanuttini, H. Campos, E. Herburger, and P. Portner, 175-198. Washington: Georgetown University Press.

Svenonius, Peter. 2002. Strains of negation in Norwegian. Working Papers in Scandinavian Syntax 69:121-146.

de Swart, Henriëtte. 2000. Scope ambiguities with negative quantifiers. In Reference and anaphoric relations, ed. Klaus von Heusinger and Urs Egli, 109-132. Dordrecht: Kluwer.

Temmerman, Tanja. 2012. Multidominance, ellipsis and quantifier scope. Doctoral Dissertation, Leiden University.

Tubau, Susagna. 2008. Negative concord in English and Romance: Syntax-Morphology interface conditions on the expression of negation. Doctoral Dissertation, University of Amsterdam.

Uriagereka, Juan. 1999. Multiple spell-out. In Working minimalism, ed. Samuel Epstein and Norbert Hornstein, 251-282. Cambridge, Massachusetts: MIT Press.

de Vries, Mark. 2009. On multidominance and linearization. Biolinguistics 3:344-403.

de Vries, Mark. 2013. Multidominance and locality. Lingua 134:149-169.

Weiß, Helmut. 2002. A quantifier approach to negation in natural languages. Or why negative concord is necessary. Nordic Journal of Linguistics 25:125-153.

Williams, Edwin. 1986. A reassignment of the functions of LF. Linguistic Inquiry 17:264-300. 
Williams, Edwin. 1988. Is LF distinct from S-structure? A reply to May. Linguistic Inquiry 135-146.

Zagona, Karen. 1988. Verb phrase syntax: A parametric study of English and Spanish. Dordrecht: Kluwer.

Zanuttini, Raffaella. 1991. Syntactic properties of sentential negation: A comparative study of Romance languages. Doctoral Dissertation, University of Pennsylvania.

Zanuttini, Raffaella. 1997. Negation and clausal structure: A comparative study of Romance languages. Oxford: Oxford University Press.

Zeijlstra, Hedde. 2004. Sentential negation and negative concord. Doctoral Dissertation, University of Amsterdam.

Zeijlstra, Hedde. 2011. On the syntactically complex status of negative indefinites. Journal of Comparative Germanic Linguistics 14:111-138.

Zeijlstra, Hedde. 2012. Not a light negation. In Proceedings of SALT 22, 545-564. 